\title{
Adsorption of Anthocyanins by Cation and Anion Exchange Resins with Aromatic and Aliphatic Polymer Matrices
}

\author{
Natalia Pismenskaya ${ }^{1, *}$, Veronika Sarapulova ${ }^{1} \mathbb{D}$, Anastasia Klevtsova ${ }^{1} \mathbb{D}$, Sergey Mikhaylin ${ }^{2}(\mathbb{D}$ \\ and Laurent Bazinet ${ }^{2}($ D) \\ 1 Kuban State University, 149 Stavropolskaya st., 350040 Krasnodar, Russia; vsarapulova@gmail.com (V.S.); \\ nastya-k1314@yandex.com (A.K.) \\ 2 Department of Food Sciences, Institute of Nutrition and Functional Foods (INAF), \\ Laboratory of Food Processing and ElectroMembrane Process (LTAPEM), University Laval, \\ Québec, QC G1V, Canada; Sergey.Mikhaylin@fsaa.ulaval.ca (S.M.); Laurent.bazinet@fsaa.ulaval.ca (L.B.) \\ * Correspondence: n_pismen@mail.ru; Tel.: +7-918-48-91-292
}

Received: 5 October 2020; Accepted: 20 October 2020; Published: 23 October 2020

check for updates

\begin{abstract}
This study examines the mechanisms of adsorption of anthocyanins from model aqueous solutions at $\mathrm{pH}$ values of 3,6, and 9 by ion-exchange resins making the main component of heterogeneous ion-exchange membranes. This is the first report demonstrating that the $\mathrm{pH}$ of the internal solution of a KU-2-8 aromatic cation-exchange resin is 2-3 units lower than the $\mathrm{pH}$ of the external bathing anthocyanin-containing solution, and the $\mathrm{pH}$ of the internal solution of some anion-exchange resins with an aromatic (AV-17-8, AV-17-2P) or aliphatic (EDE-10P) matrix is 2-4 units higher than the $\mathrm{pH}$ of the external solution. This $\mathrm{pH}$ shift is caused by the Donnan exclusion of hydroxyl ions (in the KU-2-8 resin) or protons (in the AV-17-8, AV-17-2P, and EDE-10P resins). The most significant $\mathrm{pH}$ shift is observed for the EDE-10P resin, which has the highest ion-exchange capacity causing the highest Donnan exclusion. Due to the $\mathrm{pH}$ shift, the electric charge of anthocyanin inside an ion-exchange resin differs from its charge in the external solution. At $\mathrm{pH}$ 6, the external solution contains uncharged anthocyanin molecules. However, in the AV-17-8 and AV-17-2P resins, the anthocyanins are present as singly charged anions, while in the EDE-10P resin, they are in the form of doubly charged anions. Due to the electrostatic interactions of these anions with the positively charged fixed groups of anion-exchange resins, the adsorption capacities of AV-17-8, AV-17-2P, and EDE-10P were higher than expected. It was established that the electrostatic interactions of anthocyanins with the charged fixed groups increase the adsorption capacity of the aromatic resin by a factor of 1.8-2.5 compared to the adsorption caused by the $\pi-\pi$ (stacking) interactions. These results provide new insights into the fouling mechanism of ion-exchange materials by polyphenols; they can help develop strategies for membrane cleaning and for extracting anthocyanins from juices and wine using ion-exchange resins and membranes.
\end{abstract}

Keywords: anthocyanins; structure; adsorption kinetics; adsorption isotherms, ion-exchange resin; Donnan exclusion; electrostatic interactions

\section{Introduction}

Anthocyanins are classified as polyphenols, and are composed of carbohydrate moieties (glycoside) connected to anthocyanidins (aglycone) via the oxygen of the hydroxyl group in the 3-position of anthocyanidin (Figure 1). Anthocyanidin differs in substituents, $\mathrm{R}$, which can be $-\mathrm{H}$, or $-\mathrm{OH}$, or $-\mathrm{OCH}_{3}$ groups. The carbohydrate moiety of anthocyanins most often consists of glucose but may also consist of other mono- and disaccharides, for example, rhamnose, arabinose, and galactose. It is known [1] that 
the structure and electric charge of all anthocyanins depend on the $\mathrm{pH}$ of the medium (Figure 1), due to participation of their structural elements in protonation/deprotonation reactions: in an acidic medium, anthocyanins acquire a positive charge and act as cations while in alkaline conditions, they acquire a negative charge and become anions.

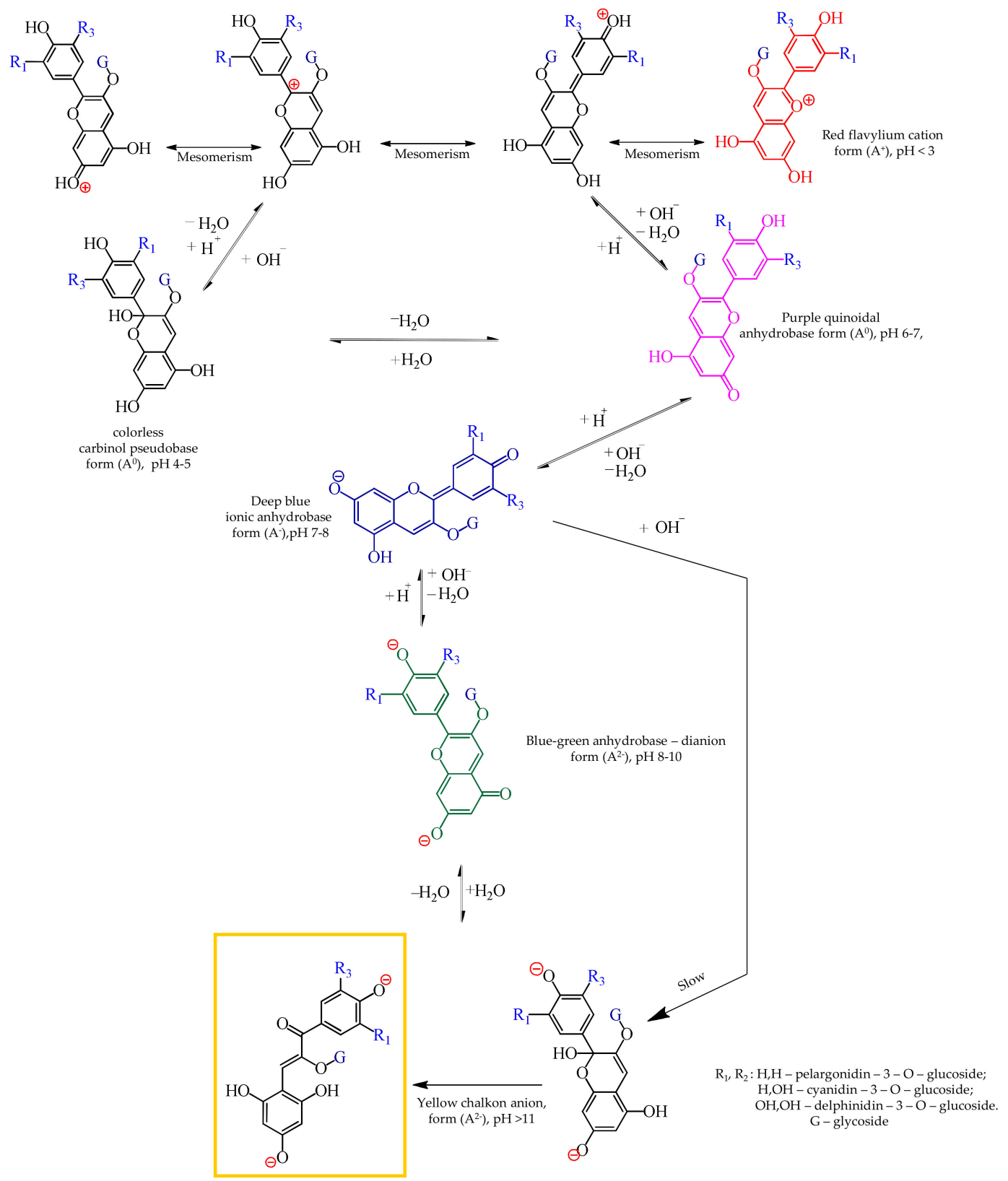

Figure 1. Structures of anthocyanins depending on the $\mathrm{pH}$ of the medium. $\mathrm{R}_{1}, \mathrm{R}_{3}$ are $-\mathrm{H}$, or $-\mathrm{OH}$, or $-\mathrm{OCH}_{3}$ groups; glycoside is glucose, rhamnose, arabinose, or galactose.

Anthocyanins are natural antioxidants [2], used to prevent and treat cancer [3] and diabetes [4], as well as cardiovascular [5] and neurodegenerative diseases [6]. They are also actively used as food dyes [7,8], colorimetric indicators of food freshness [9], cosmetics, and dietary supplements for detoxification of the human body and increasing its immunity [10]. The unique properties of these substances have caused an avalanche-like growth in related publications. Indeed, in 2000, Scopus indexed 314 publications on mainly the medical properties of these substances, but since 2015, the number of publications has exceeded 2000 per year. The main focus of this research has shifted to the preservation of anthocyanins and other polyphenols in juices and wines during 
their production [11-13] as well as to anthocyanins extraction from natural sources (primarily from winemaking waste [4]); in processing berries, fruits, vegetables [14-20]; or in discoloration of food [21,22] and waste water [23-25].

Traditional extraction methods for removing anthocyanins use acidified water-alcohol mixtures or other organic solvents [26,27]. However, these methods do not always provide the desired degree of purity: the recovery liquid media contains anthocyanins in small quantities and/or as a part of a mixture with many other components. Using sorption methods [28-30] in combination with membrane (nanofiltration, ultrafiltration, electrodialysis) technologies [14,30,31] provides higher efficiency and allows selective separation of anthocyanins and other polyphenols from multicomponent natural mixtures. Several reviews exist on the sorption and membrane methods used to extract and purify anthocyanins $[15,29,32,33]$. Activated carbon and nonpolar or weakly polar porous polymer resins are the most common adsorbents [15,34-37]. Special attention is paid to the specific surface area, pore, and granule sizes of these adsorbents [38], as well as the temperature of the adsorption process [39,40]. A number of researchers also highlighted that the nature of the adsorbent can significantly affect the performance of the process $[15,41,42]$. Enhanced adsorption can be achieved by $\pi-\pi$ (stacking) and Van der Waals interactions between the aromatic rings of polyphenols and the aromatic polymer matrix of adsorbents [42,43]. Consequently, increasing the $\mathrm{pH}$ above $p K_{a}\left(K_{a}\right.$ is the phenol dissociation constant) is a common method for regenerating nonpolar or weakly polar adsorbents [44-46].

In recent years, technologies using ion-exchange resins (IERs) [15,47-51] or ion-exchange membranes (a type of flat resin) [18-20] for the extraction and purification of phenols, and anthocyanins, in particular, have been increasingly adopted. These materials differ from adsorption resins only by having polar fixed groups. In the case of anion-exchange resins, these groups have a positive electric charge while in cation-exchange resins, these groups are negatively charged. Furthermore, it was established that using ion-exchange resins increases the selectivity and efficiency of phenol [50,52-54], polyphenol, and anthocyanin $[13,47,48,54-59]$ adsorption compared to nonpolar macroporous resins and activated carbon. IERs also allow polyphenols to be separated from other components of processed liquid media [60,61]. Moreover, purification of anthocyanins increases their antioxidant activity [62] but traditional eluents for the extraction of phenolic compounds from nonpolar resins are often unsuitable in the case of IER [54].

Current investigations suggest that phenols enter into $\pi-\pi$ (stacking) and Van der Waals interactions with ion-exchange materials [54,55], in a similar way as with nonpolar resins. Therefore, the sorption increases when switching a polymer matrix of IERs and membranes from aliphatic (e.g., polyacrylamide) to aromatic (polystyrene) [63]. In contrast to nonpolar adsorbents, hydrogen bonds are formed between fixed IER groups and phenol hydroxyl groups $[64,65]$. The fixed groups of ion-exchange materials then form electrostatic interactions with phenols, when the latter are in ionic form in the solution [42,54-58]. Furthermore, the proportion of ionic forms depends on the dissociation constants $p K_{a}$ of the polar groups of polyphenols and the $\mathrm{pH}$ of the solution [13,47,48,54-59]. However, there is no consensus in the literature concerning the relationship between the $\mathrm{pH}$ of a processed solution and the adsorption capacity of an IER. For example, using cation-exchange resins to extract biogenic amines and sulfates from wine at $\mathrm{pH} 3.5$ [66] or protons from fruit juices [67] does not lead to adsorption of anthocyanins [65] or this adsorption is negligible [66] despite the fact that anthocyanins are cations in these liquid media. Ghafari et al. [54] found that phenol is equally adsorbed by anion-exchange materials at both $\mathrm{pH} 6$ and 11 of the external solution. Since the $p K_{a}$ of phenol is 9.9, these authors [54] concluded that phenol was unlikely to be deprotonated at $\mathrm{pH} 6$, so electrostatic interactions between phenol and the anion-exchange material were unlikely. Thus, different adsorption mechanisms prevail at $\mathrm{pH} 6$ and 11: formation of hydrogen bonds at $\mathrm{pH} 6$ and electrostatic interactions at $\mathrm{pH} 11$.

We performed this study to clarify the main mechanisms underlying the adsorption of anthocyanins by IERs from aqueous solutions with different $(3,6$, and 9) $\mathrm{pH}$ values. The study includes the identification of the structure of anthocyanins in the external solution and within the IERs having aromatic or aliphatic matrices and differing in porosity and exchange capacity. We will analyze the 
kinetics and equilibrium of the anthocyanin sorption by the resins, taking into account the structure and electric charge of anthocyanins.

\section{Results and Discussion}

\subsection{Effect of $\mathrm{pH}$ on Anthocyanin Structure in External Solutions and Ion-Exchange Resins}

\subsubsection{In External Solutions}

External solutions were prepared from an aqueous anthocyanins mixture. According to the manufacturer (DOO "Frutarom Etol", Skofja vas, Slovenia), it was extracted from grape pulp. This extract has $\mathrm{pH} 2.95 \pm 0.05$ and, according to high-performance liquid chromatography (HPLC) analysis, mainly contains the anthocyanins cyanidin and peonidine (Table 1). Their structures at $\mathrm{pH} 3$ are shown in Figure 2. The $\mathrm{pH}$ of external solutions was adjusted to $3 \pm 0.05,6 \pm 0.05$, and $9 \pm 0.05$ by adding $\mathrm{NaOH}$.

Table 1. Composition of the anthocyanin extract from grape pulp.

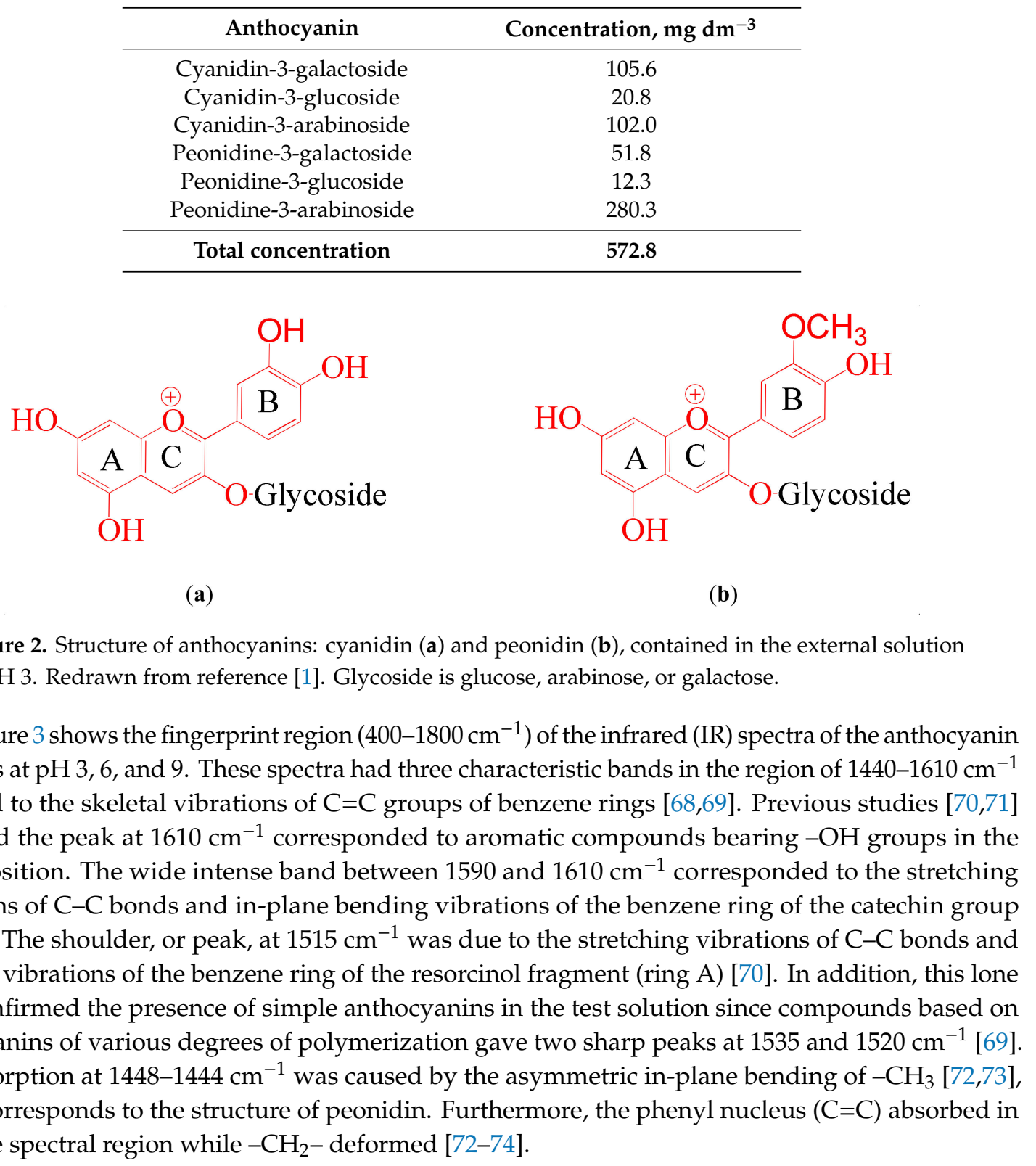




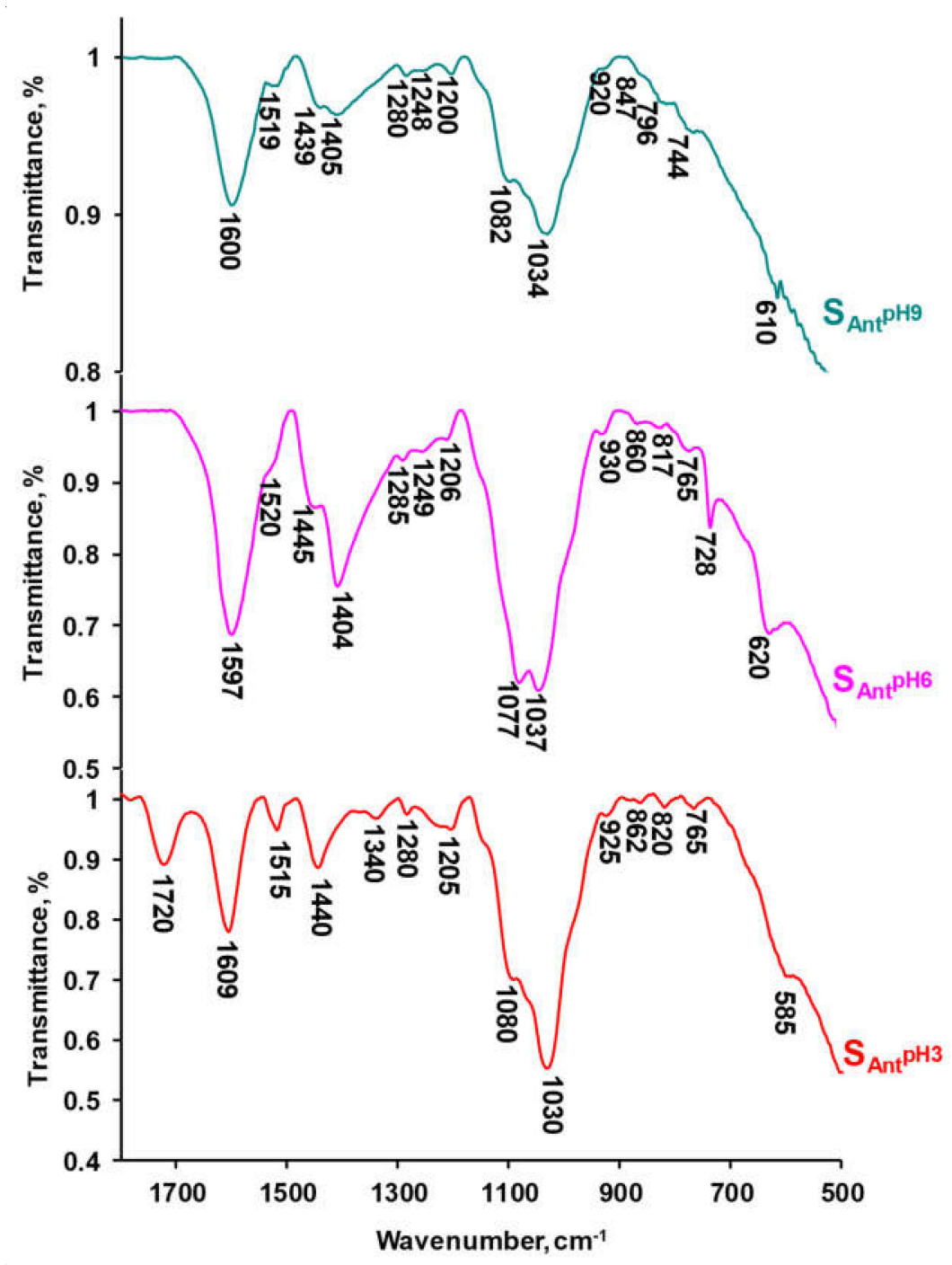

Figure 3. Effect of $\mathrm{pH}$ on the shape of the attenuated total reflection-Fourier transform infrared (ATR-FTIR) spectra in the anthocyanin fingerprint region $\left(400-1800 \mathrm{~cm}^{-1}\right)$.

The asymmetric and symmetric vibrations of the $\mathrm{C}-\mathrm{O}-\mathrm{C}$ bond of the pyran ring manifested in the ranges of 1260-1285 $\mathrm{cm}^{-1}$ and 1025-1198 cm-1 , respectively [69]. The band between 920 and $930 \mathrm{~cm}^{-1}$ corresponded to the skeletal vibration involving $\alpha-1,4$-glycosidic bond $(\mathrm{C}-\mathrm{O}-\mathrm{C})$ [75]. The catechin fragment with two neighboring $\mathrm{O}-\mathrm{H}$ groups also corresponded to the bands at 1280 and $1245 \mathrm{~cm}^{-1}[76]$. The out-of-plane and in-plane bending vibrations of $\mathrm{C}-\mathrm{H}$ in the aromatic ring corresponded to the $670-900 \mathrm{~cm}^{-1}$ region [77]. The peak between 735 and $770 \mathrm{~cm}^{-1}$ was typical of the bending vibrations of the $\mathrm{C}-\mathrm{H}$ bond of orthosubstituted aromatic compounds [78]. In the $400-750 \mathrm{~cm}^{-1}$ range, the peaks were caused by out-of-plane and in-plane bending vibrations of the $\mathrm{C}-\mathrm{O}-\mathrm{H}$ bond of the catechin fragment, with the out-of-plane vibrations being assigned to higher wave numbers than the in-plane vibrations [76].

The structural features of anthocyanins were present since, at $\mathrm{pH} 3$, the $1720 \mathrm{~cm}^{-1}$ peak of the IR spectrum corresponded to the positively charged $\mathrm{C}=\mathrm{O}^{+}$group [78]. At $\mathrm{pH} 6$ and 9, this peak disappeared, and another peak whose intensity decreased with increasing $\mathrm{pH}$ appeared in the region of 1400-1410 $\mathrm{cm}^{-1}$. These changes in the spectra indicated the transformation of the $-\mathrm{C}=\mathrm{O}$ group of the chromenylium cycle ( $\mathrm{pH} 3$ ) to the-O-group ( $\mathrm{pH} 6$ and 9), which had no electric charge [79]. The spectra obtained for the anthocyanin solutions at $\mathrm{pH} 3$ and 6 produced similar peaks in the $860 \mathrm{~cm}^{-1}$ and $760 \mathrm{~cm}^{-1}$ regions. At $\mathrm{pH} \mathrm{9,} \mathrm{these} \mathrm{peaks} \mathrm{shift} \mathrm{to} 867 \mathrm{~cm}^{-1}$ and $775 \mathrm{~cm}^{-1}$. In addition, 
this spectrum had peaks at $850 \mathrm{~cm}^{-1}$ and $610 \mathrm{~cm}^{-1}$, which are absent at lower $\mathrm{pH}$ values. Increasing the $\mathrm{pH}$ of the external solution transformed the IR spectra in the range of $670-900 \mathrm{~cm}^{-1}$ indicating changes in the side groups of the chromenylium cycle and benzene rings [80]. At $\mathrm{pH}$ 6, colorless pseudo bases with non-protonated-OH groups prevailed in the anthocyanin mixtures, yet some in the quinoid form, which has one of the phenolic hydroxyl groups in the deprotonated state; $-\mathrm{O}^{-}$, was also found. At $\mathrm{pH} 9$, quinoid forms predominated in the anthocyanin mixtures; however, a certain number of phenolates were detected which had not one but two deprotonated $-\mathrm{O}^{-}$groups. In addition, some chalcone forms were present. The chalcones formed due to quinoid hydrolysis, which was accompanied by a rupture of the chromene cycle.

The IR-spectroscopy data agree with the colorimetric scale (Figure 4) obtained for different $\mathrm{pH}$ values of the anthocyanin mixture. According to this scale, acidic solutions $(1<\mathrm{pH}<3)$ are bright red, which is typical of the pyrylium salt of anthocyanins and is an indicator of the dominance of flavylium cations in the solution. As the $\mathrm{pH}$ increased from 3 to 7 , the color gradually changed to purple due to an increase in the proportion of the quinoid form, which has no electric charge. In the range of pH 7 to 9, shades of blue typical of the anthocyanin quinoid form, which is a singly charged anion, became increasingly predominant. Around $\mathrm{pH} 10$, shades of yellow and green prevailed, indicating the presence of doubly charged anions in the solution. A small part of this was the chalconoid form with the ruptured chromene cycle. At higher $\mathrm{pH}$ values, chalcone anions became the dominant anthocyanin forms producing solutions that became more and more yellow. This scale confirmed the well-known [1] relationship between the structure and the color of anthocyanins (Figure 1). However, the shift to the blue and green colors corresponding to singly charged anions of anthocyanins is observed in a slightly more alkaline region than indicated by Ribéreau et al [1]. The cause for this difference was that each of the anthocyanins in the model mixture had their own constants of protonation/deprotonation reactions of radicals. Therefore, the color shifts are less abrupt compared to separated substances or substances alone.

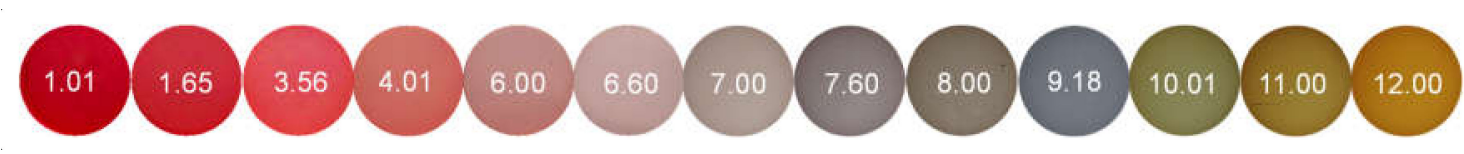

Figure 4. Effect of $\mathrm{pH}$ on the color of anthocyanin solutions. The $\mathrm{pH}$ values of the solutions are indicated for each color.

\subsubsection{In Ion-Exchange Resins}

The following IERs with typical ion-exchange polymer matrices and fixed groups (Table 2) were studied. The anion-exchange resin EDE-10P (manufacturer: PJSC "Uralchimplast", Russia) was made by polycondensation of polyethylene polyamines (PEPAs) with epichlorohydrin $(\mathrm{ECH})$ [81]. This resin had an aliphatic matrix and contained primary, secondary, and tertiary amines and a small number of quaternary ammonium bases as fixed groups. The other resins (manufacturers: TD "Ural Chemical Company", Russia; ISC "Azot", Ukraine) were made by suspension polymerization.

Table 2. Some characteristics of the ion-exchange resins determined in the present study.

\begin{tabular}{|c|c|c|c|c|c|}
\hline IERs & Fixed Groups & $\begin{array}{l}\text { Polymer } \\
\text { Matrix }\end{array}$ & $\begin{array}{l}\text { True Density, } \\
\qquad \mathrm{g} \mathrm{cm}^{-3}\end{array}$ & $\begin{array}{l}\text { Water Content, } \\
\mathrm{g}_{\mathrm{H} 2 \mathrm{O}} / \mathrm{g}_{\text {wet }}, \%^{1}\end{array}$ & $\begin{array}{l}\text { Total Ion-Exchange } \\
\text { Capacity, mmol } \mathrm{cm}^{-3}\end{array}$ \\
\hline & \multicolumn{5}{|c|}{ Anion-exchange resins } \\
\hline EDE-10P & $=\mathrm{NH}^{+},-\mathrm{NH}_{2}{ }^{+}, \equiv \mathrm{N}$ & $\mathrm{ECH}+\mathrm{PEPA}$ & $1.17[82]$ & 46 & $2.34[83]$ \\
\hline AV-17-2P & $-\mathrm{N}^{+}\left(\mathrm{CH}_{3}\right)_{3}$ & DVB2 $\%+P S$ & $1.06^{1}$ & 61 & $0.80 \pm 0.02[84]$ \\
\hline AV-17-8 & $-\mathrm{N}^{+}\left(\mathrm{CH}_{3}\right)_{3}$ & DVB8\%+PS & 1.13 [82] & 45 & $1.12 \pm 0.02[84]$ \\
\hline & \multicolumn{5}{|c|}{ Cation-exchange resin } \\
\hline KU-2-8 & $-\mathrm{SO}_{3}^{-}$ & DVB8\%+PS & $1.25[82]$ & 56 & $1.80 \pm 0.01[84]$ \\
\hline
\end{tabular}

${ }^{1}$ This value is found by the method described in reference [85]. Abbreviations: polyethylene polyamine (PEPA), epichlorohydrin $(\mathrm{ECH})$, divinylbenzene (DVB). 
Their polymer matrixes consisted of polystyrene (PS) regularly crosslinked with divinylbenzene (DVB) at a fraction of $2 \%(\mathrm{AV}-17-2 \mathrm{P})$ or $8 \%(\mathrm{AV}-17-8, \mathrm{KU}-2-8)$ [86]. The aromatic anion-exchange resins contained mainly quaternary amines and small amounts of secondary and tertiary amines as fixed groups. The cation exchange resin KU-2-8 contained sulfonic groups. The true density and total ion-exchange capacities of the water-swollen IERs are shown in Table 2. The diameter of the resin beads is in the range of $0.3-0.5 \mathrm{~mm}$.

Figure 5 shows the IR-spectra of samples of the aliphatic anion-exchange resin EDE-10P. Prior to the experiment, one resin was equilibrated with deionized water $\left(\mathrm{EDE}-10 \mathrm{P}_{\mathrm{W}}\right)$, and the other with an anthocyanin solution at $\mathrm{pH} 3\left(\mathrm{EDE}-10 \mathrm{P}_{\mathrm{Ant}}{ }^{\mathrm{pH} 3}\right)$. These and other IR spectra of IER were interpreted using the data from several previous studies [78,87-89]. The weak double band typical of the bending vibrations of $\mathrm{N}-\mathrm{H}$ appeared in the 1614 to $1633 \mathrm{~cm}^{-1}$ region of the EDE-10P $\mathrm{W}_{\mathrm{W}}$ IR spectra, indicating the presence of secondary and primary amines in the resin. Numerous peaks characteristic of $\mathrm{C}-\mathrm{N}$ stretching occurred between 1020 and $1174 \mathrm{~cm}^{-1}$, also indicating the presence of weakly basic fixed amino groups in the anion exchange resin $[54,90]$.

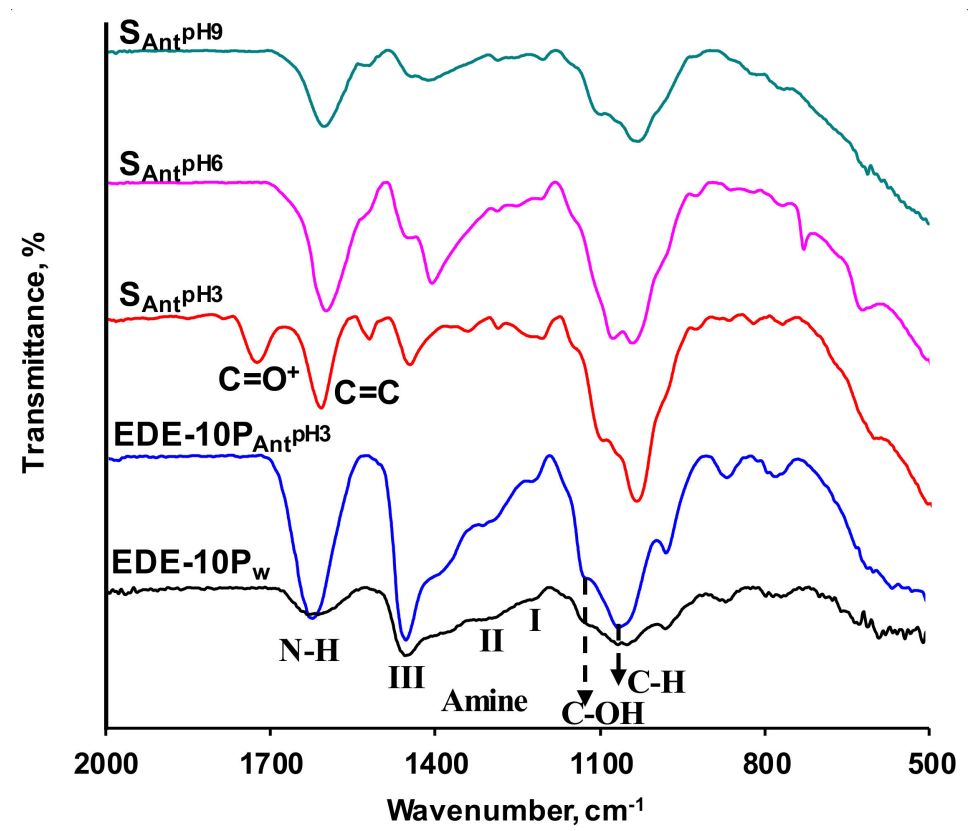

Figure 5. IR spectra of the EDE-10P samples equilibrated with deionized water (indicated by the subscript $\mathrm{W}$ ) and an anthocyanin solution at $\mathrm{pH} 3$ (indicated by the subscript ${ }_{A n t}{ }^{\mathrm{pH} 3}$ ). The IR spectra of the anthocyanin solutions at $\mathrm{pH} 3,6$, and 9 (indicated by the subscript $\mathrm{S}_{\mathrm{Ant}}{ }^{\mathrm{pHi}}$ ) are shown for comparison.

Furthermore, peaks appeared in the following regions of the IR-spectra of EDE-10P $\mathrm{P}_{\mathrm{W}}$ : (1) 2963 to $2844 \mathrm{~cm}^{-1}$, corresponding to the asymmetric and symmetric stretching vibrations of $-\mathrm{CH}_{2}$ groups; (2) $1459 \mathrm{~cm}^{-1}$, corresponding to the bending vibrations of C-H groups; and (3) 1030 to $1020 \mathrm{~cm}^{-1}$ corresponding to stretching vibrations of the $\mathrm{C}-\mathrm{OH}$ bond. It is well known [91] that these are the main groups constituting the EDE-10P resin. For the EDE- $10 \mathrm{P}_{\mathrm{Ant}}{ }^{\mathrm{pH} 3}$ sample, the peaks at 1614 and $1633 \mathrm{~cm}^{-1}$ overlapped with intense maxima typical of $\mathrm{C}=\mathrm{C}$ bonds in the benzene rings of anthocyanins. The intensity of the other peaks typical of EDE-10P $\mathrm{P}_{\mathrm{W}}$ was enhanced due to the adsorption of anthocyanins, which included glycosides with $-\mathrm{CH}_{2}, \mathrm{C}-\mathrm{H}$, and $\mathrm{C}-\mathrm{OH}$ groups. In the EDE-10P ${ }_{\text {Ant }}{ }^{\mathrm{pH} 3}$ IR spectrum it was not possible to distinguish the peaks at 1722 and $1519 \mathrm{~cm}^{-1}$, which are characteristic of the positively charged flavylium cation form of anthocyanins; however, there were peaks at 870 and $780 \mathrm{~cm}^{-1}$, which are characteristic of anthocyanin with non-protonated -OH groups and some number of deprotonated phenolic hydroxyl groups. As shown in Figure 5, the EDE- $10 \mathrm{P}_{A n t}{ }^{\mathrm{pH} 6}$ and EDE-10P ${ }_{A n t}{ }^{\mathrm{pH} 9}$ IR spectra differed from the EDE- $10 \mathrm{P}_{A n t}{ }^{\mathrm{pH} 3}$ spectrum in a shift 
of these peaks to the 867 and $775 \mathrm{~cm}^{-1}$ regions with increased intensity, as well as the peaks appearing at 827 and $611 \mathrm{~cm}^{-1}$, indicating the increase of deprotonated phenolic hydroxyl groups.

IR spectroscopic data agreed with the observed change in EDE-10P resin color depending on the $\mathrm{pH}$ of the external solution. Indeed, this resin in the chloride form and equilibrated with deionized colorless water was orange in color (Figure 6a). The EDE-10 $\mathrm{P}_{\mathrm{Ant}}{ }^{\mathrm{pH} 3}$ resin sample in contact with the carmine red solution of anthocyanins ( $\mathrm{pH} 3$ ) acquired a purple-brown hue (Figure $6 \mathrm{~b})$. The EDE-10P $\mathrm{Ant}^{\mathrm{pH} 6}$ resin sample equilibrated with the purple solution of anthocyanins $(\mathrm{pH} 6)$ turned a yellow-green (khaki) color (Figure 6c). The EDE-10 $\mathrm{P}_{\mathrm{Ant}}{ }^{\mathrm{pH} 9}$ resin sample equilibrated with the gray-blue solution of anthocyanins ( $\mathrm{pH} 9$ ) and became yellow-brown (Figure 6d). The bright color of the pristine resin made it difficult to interpret the data obtained; however, this was achieved by taking into account the rules of color science [92]. The registered colors were produced by mixing red-orange hues (Figure 6a) with blue (Figure 6b), with green (Figure 6c), and with yellow (Figure 6d). This indicated that single-charged anions of the quinoid form of anthocyanins (EDE-10P ${ }_{\mathrm{Ant}}{ }^{\mathrm{pH} 3}$ ), the blue isomer of the doubly charged chalcone anion (EDE-10P $\mathrm{Ant}^{\mathrm{pH} 6}$ ), or the yellow doubly charged isomer of the chalcone anion ruptured the chromene cycle prevailing in the resin.

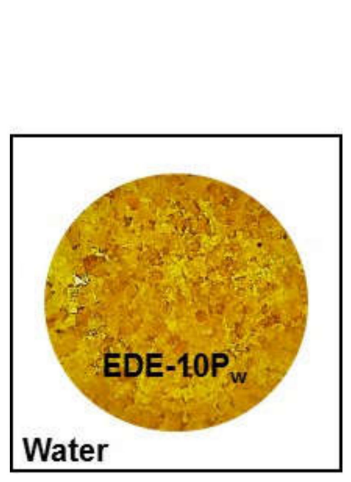

(a)

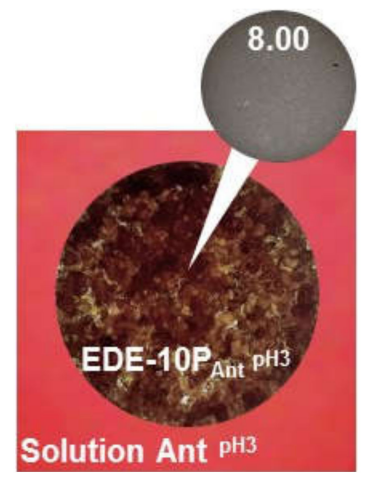

(b)

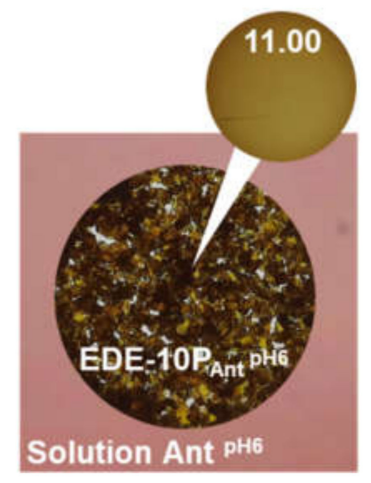

(c)

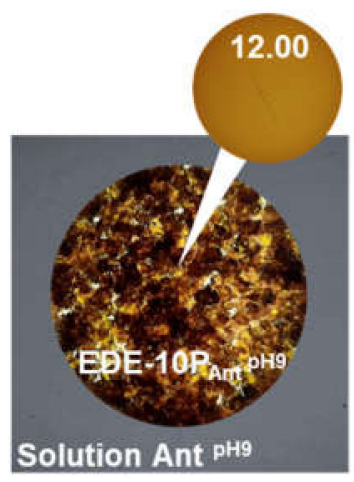

(d)

Figure 6. Color of the anion-exchange resin EDE-10P in the $\mathrm{Cl}^{-}$form, equilibrated with deionized water (a) and model anthocyanin solutions at pH 3 (b), 6 (c), and 9 (d). The upper circles represent the closest anthocyanin color in solution on the colorimetric scale (Figure 4); the number inside the circle indicates the $\mathrm{pH}$ value corresponding to that color of the solution.

IR spectroscopy of anthocyanins adsorbed by the aromatic resins AV-17-2P, AV-17-8, and KU-2-8 was an even greater challenge than for the aliphatic EDE-10P resin due to the very similar chemical structure between the IER polymer matrix and anthocyanin. Analysis of these spectra (data not shown) showed an increase in the absorption intensity at the wavelengths associated with the presence of aromatic $-\mathrm{C}=\mathrm{C}-$ bonds or characteristic of glucosides. These intense extended peaks shifted to the ultraviolet region, indicating the presence of the $\pi-\pi$ (stacking) interactions of anthocyanin aromatic rings with poly(styrene-divinylbenzene) IER matrix [87], and overlapped with the wavelengths (1722 and $1519 \mathrm{~cm}^{-1}$ ) assigned to the positively charged flavilium cation. Thus, the colors that the aromatic resins have acquired gave more information about the structure and electric charge of the anthocyanins adsorbed by them in comparison with the IR spectra.

In water and aqueous solutions of strong electrolytes, the aromatic AV-17-2P resin was white in color (Figure 7a). Therefore, color changes associated with conversions in the anthocyanin structure were not distorted by overlapping color hues. The AV-17-2P $\mathrm{Ant}^{\mathrm{pH} 3}$ resin sample in contact with the carmine red solution of anthocyanins $(\mathrm{pH} 3$ ) acquired a purple color (Figure $7 \mathrm{~b}$ ) corresponding to $\mathrm{pH} 6.0$ on the colorimetric scale. This meant that anthocyanins were in the form of flavilium cations in the solution, but in the resin changed to the purple phenolate of the quinoid form, which has no electric charge. The AV-17-2 $\mathrm{P}_{\mathrm{Ant}}{ }^{\mathrm{pH} 6}$ resin sample equilibrated with the $\mathrm{pH} 6$ anthocyanin solution, where anthocyanins were present as the purple phenolate of the quinoid form bearing no electric 
charge, acquiring a gray-blue color (Figure 7c). This color corresponded to a $\mathrm{pH}$ value of 9 on the colorimetric scale, where most of the anthocyanins were transformed into blue quinoid anions with a charge of $1^{-}$. In the $\mathrm{pH} 9$ solution, anthocyanins were present as a mixture of neutral molecules and singly charged anions. The AV-17-2 $\mathrm{P}_{\mathrm{Ant}}{ }^{\mathrm{pH} 9}$ resin sample equilibrated with this solution became greenish-yellow (Figure 7d). This color corresponded to a $\mathrm{pH}$ value of 11 according to the colorimetric scale, indicating that the resin contained blue-green and yellow isomers of the chalcone anion bearing an electric charge of $2^{-}$.

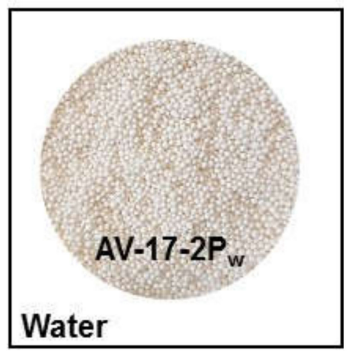

(a)

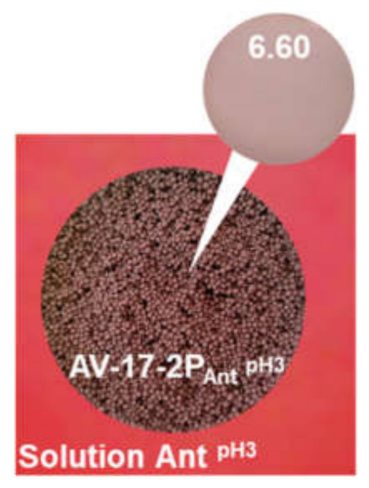

(b)

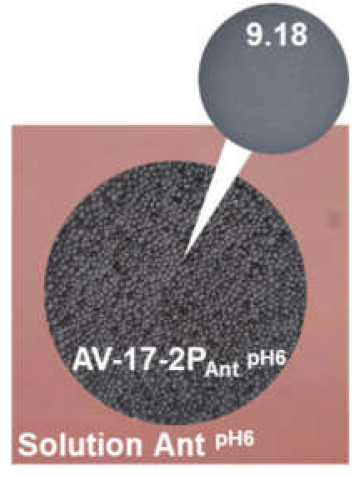

(c)

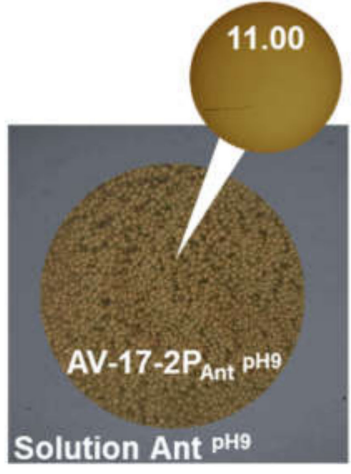

(d)

Figure 7. Color of the anion-exchange resin AV-17-2 in the $\mathrm{Cl}^{-}$form, equilibrated with deionized water (a) and anthocyanin solutions at pH 3 (b), 6 (c), and 9 (d). The upper circles represent the closest anthocyanin color on the colorimetric scale in solution (Figure 4); the number inside the circle indicates the $\mathrm{pH}$ value corresponding to that color.

While the colorimetric analysis of anthocyanin charge in the AV-17-8 resin (data not shown) was similar to those obtained for AV-17-2P, the behavior of the cation-exchange resin equilibrated with the anthocyanin solutions differs from the anion-exchange resin. The color of the KU-2- $8_{\mathrm{Ant}}{ }^{\mathrm{pH} 3}$ sample turned dark red, corresponding to $\mathrm{pH} 1.65$ on the colorimetric scale (Figure $8 \mathrm{~b}$ ). The KU-2- $8_{\mathrm{Ant}}{ }^{\mathrm{pH} 6}$ resin sample became a purple-pink color, corresponding to $\mathrm{pH} 4$ on the colorimetric scale (Figure $8 \mathrm{c}$ ). The KU-2-8 $\mathrm{Ant}^{\mathrm{pH} 9}$ resin sample turned brownish-orange in color (Figure $8 \mathrm{~d}$ ). These results indicate that at $\mathrm{pH} 3$ of the external solution, anthocyanins in the cation-exchange resin are singly charged cations. At pH 6 and 9, they are a mixture of colorless pseudo bases with no electric charge and a small number of anthocyanin cations, or a small number of anthocyanin anions.

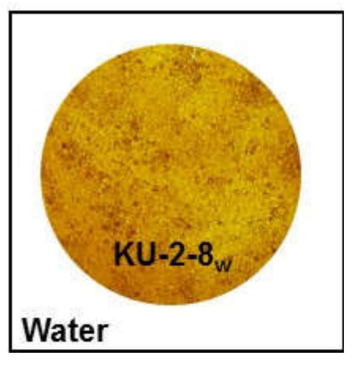

(a)

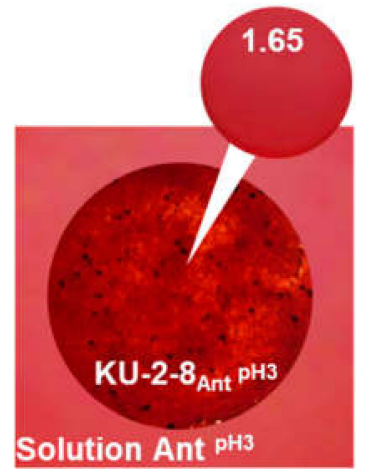

(b)

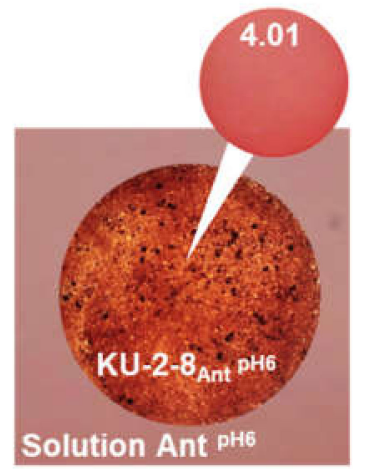

(c)

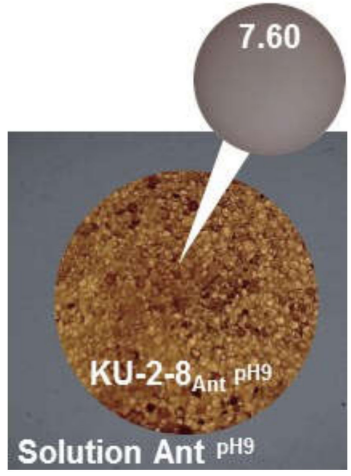

(d)

Figure 8. Color of the cation-exchange resin $\mathrm{KU}-2-8$ in the $\mathrm{Na}^{+}$form, equilibrated with deionized water (a) and anthocyanin solutions at pH 3 (b), 6 (c), and 9 (d). The upper circles represent the closest anthocyanin color on the colorimetric scale in solution (Figure 4); the number inside the circle indicates the $\mathrm{pH}$ value corresponding to that color. 
Thus, the data presented in Figures 6-8 indicate that the structure of anthocyanins inside ion-exchange resins differs markedly from the structure of these substances in external solutions. The structure in anion-exchange resins (Figures 6 and 7) corresponds to $\mathrm{pH}$ values that are 2-3 units higher than in external solutions of anthocyanins. Conversely, the structure of anthocyanins in a cation exchange resin (Figure 8) corresponds to $\mathrm{pH}$ values that are 2-3 units lower than in external solutions of anthocyanins. This phenomenon is similar to mechanisms already reported for ion-exchange membrane fouling by red wine components, primarily anthocyanins [93]. Hence, the reason for the $\mathrm{pH}$ shift of the internal solution of ion-exchange membranes and resins is the well-known [85] Donnan (electrostatic) exclusion of coions. Figure 9 illustrates the Donnan effect in ion-exchange materials if coions are the products of protonation/deprotonation reactions involving water molecules. The scheme is presented when the $\mathrm{pH}$ of the external solution is 6 and where the electric charge of anthocyanins is zero $\left(\mathrm{Ant}^{0}\right)$. In the case of anion-exchange resin (Figure 9a), the coions are protons with the same electric charge as positively charged fixed groups of anion-exchange resins. These protons are excluded from anion-exchange resins due to the Donnan effect. As a result, the $\mathrm{pH}$ of the anion-exchange resin internal solution increases. Once in this alkaline medium, electrically neutral anthocyanin molecules are transformed into anions ( $\left(\mathrm{Ant}^{-}\right.$) due to the deprotonation of phenolic hydroxyl groups. The higher the concentration of fixed groups, the more intense the Donnan exclusion of protons [85]. That is why anthocyanins in EDE-10P resin, which is characterized by the highest exchange capacity (Table 2), have a more negative charge than in resins AV-17-2P and AV-17-8.

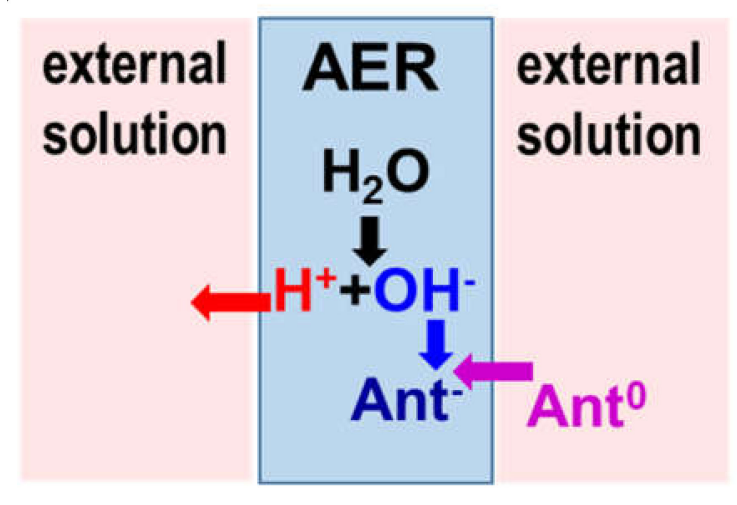

(a)

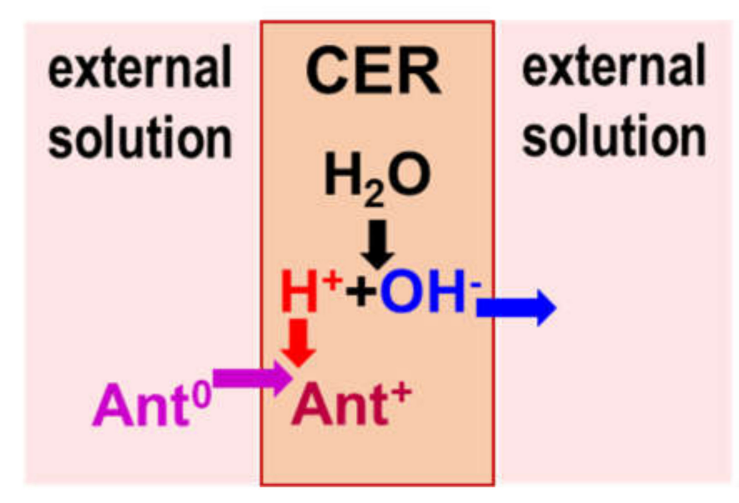

(b)

Figure 9. Schematic representation of the $\mathrm{pH}$ shift phenomenon in (a) anion-exchange resins (AERs), (b) cation-exchange resins (CERs), and external anthocyanin solutions ( $\mathrm{pH}$ 6) surrounding the resins due to the Donnan exclusion of coions $\left(\mathrm{H}^{+}\right.$or $\left.\mathrm{OH}^{-}\right)$that are the products of protonation/deprotonation reactions.

Conversely, protons going from anion-exchange resin into the external solution lowers its $\mathrm{pH}$, which can transform some of the neutral anthocyanin molecules into cations $\left(\mathrm{Ant}^{+}\right)$. In cation-exchange resins (Figure 9b), the coions are hydroxyl ions and Donnan exclusion of hydroxyl ions decreases the $\mathrm{pH}$ of the resin's internal solution. In this acidic medium, neutral anthocyanin molecules (quinoidal anhydrobases) are transformed into another neutral form (carbinol pseudobases) or modified into cations. At the same time, hydroxyl ions entering the external solution participate in the deprotonation reactions of neutral anthocyanin molecules, generating a certain number of anthocyanin anions in the external solution. Note that these anthocyanin anions (for cation-exchange resin) and cations (for anion-exchange resin) in the solution at the surface of an ion-exchange material can decrease the adsorption capacity of a resin if they are not quickly and consistently removed to the solution volume, for example, by mixing. Similar to anthocyanins, phenols, amino acids, carboxylic acids, polybasic organic acids, and other ampholytic substances that are components of juices and wines [1] participate in protonation/deprotonation reactions with water, also affecting the $\mathrm{pH}$ of the internal 
solution of ion-exchange materials [93-96]. This particular effect is one of the reasons not previously discussed that produces differences in anthocyanin adsorption between single solutions and mixtures, for example, with amino acids $[55,56]$.

The $\mathrm{pH}$ values of external and internal solutions of IERs, as well as the electric charges of anthocyanins in these mediums, are summarized in Table 3. Knowing these charges and $\mathrm{pH}$ will help interpret the kinetic adsorption isotherms presented in the next section.

Table 3. Some characteristics of the systems under study.

\begin{tabular}{|c|c|c|c|c|c|}
\hline & $\begin{array}{l}\text { External } \\
\text { Solution }\end{array}$ & KU-2-8 & AV-17-8 & AV-17-2P & EDE-10P \\
\hline $\mathrm{pH}$ & $3.00 \pm 0.05$ & $2.5 \pm 0.5$ & $7.0 \pm 0.6$ & $6.6 \pm 0.4$ & $8 \pm 1$ \\
\hline $\begin{array}{c}\text { Anthocyanins' } \\
\text { electrical charge }\end{array}$ & $1+$ & $1+$ & 0 & 0 & $\begin{array}{c}0, \\
1-(\text { a small amount })\end{array}$ \\
\hline${ }^{*} C_{I E R} / C_{S O}(\mathrm{t}=180 \mathrm{~min})^{1}$ & - & $20 \pm 1$ & $13 \pm 1$ & $15 \pm 1$ & 29 \\
\hline $\mathrm{pH}$ & $6.00 \pm 0.05$ & $4.0 \pm 0.5$ & $8 \pm 1$ & $8.0 \pm 0.5$ & $10.5 \pm 0.5$ \\
\hline $\begin{array}{l}\text { Anthocyanins' } \\
\text { electrical charge }\end{array}$ & 0 & $\begin{array}{c}0, \\
1+(\text { a small amount })\end{array}$ & $1-$ & $1-$ & $2-$ \\
\hline${ }^{*} C_{I E R} / C_{S O}(\mathrm{t}=180 \mathrm{~min})^{1}$ & - & $10 \pm 1$ & $22 \pm 1$ & $22 \pm 1$ & $26 \pm 1$ \\
\hline $\mathrm{pH}$ & $9.00 \pm 0.05$ & $7.6 \pm 0.6$ & $10.5 \pm 1$ & $11.0 \pm 0.5$ & $12 \pm 1$ \\
\hline $\begin{array}{c}\text { Anthocyanins' } \\
\text { electrical charge }\end{array}$ & $1-$ & $\begin{array}{c}0, \\
1-(\text { a small amount })\end{array}$ & $2-$ & $2-$ & $2-$ \\
\hline${ }^{*} C_{I E R} / C_{S O}(\mathrm{t}=180 \mathrm{~min})^{1}$ & - & $12 \pm 1$ & $22 \pm 1$ & $22 \pm 1$ & $14 \pm 1$ \\
\hline
\end{tabular}

${ }^{1}$ The adsorption factor of anthocyanins, achieved after $180 \mathrm{~min}$ of ion-exchange resins' (IERs') contact with an external solution, the concentration of anthocyanins in which $C_{s 0}$ was $40 \mathrm{mg} \mathrm{dm}^{-3}$. The procedure for determining the concentration of anthocyanins in resins $C_{I E R}$ is described in Section 3.3.1.

\subsection{Effect of the External Solution $\mathrm{pH}$ on Anthocyanin Adsorption by Ion-Exchange Resins}

Figure 10 shows the kinetics of anthocyanin adsorption by anion- and cation-exchange resins

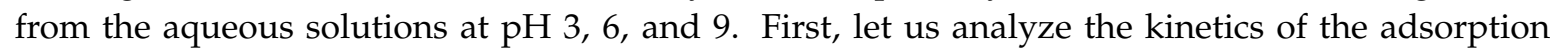
of anthocyanins by aromatic resins, which are produced from a copolymer of polystyrene with divinylbenzene. It should be noted that the fixed groups of KU-2-8 are negatively charged sulfonic groups, whereas positively charged AV-17-8 are mainly quaternary ammonium bases. The AV-17-2P resin has the same fixed groups and less crosslinking (therefore, larger pores) than AV-17-8. The ion exchange capacity of these resins in a swollen state grows in the following order: AV-17-2P $<$ AV-17-8 $<$ KU-2-8.

Anthocyanin flavilium cations, $\mathrm{Ant}^{+}$, which are coions for anion-exchange resin, dominate in the acidic external solution ( $\mathrm{pH} 3$ ) of the aromatic resins AV-17-2P and AV-17-8. However, when moving into the internal solution of AV-17-2P and AV-17-8, they are transformed into the uncharged molecules, $\mathrm{Ant}^{0}$ (Table 1). The adsorption of the molecular form of anthocyanins to these resins is mainly accomplished through $\pi-\pi$ (stacking) interactions of the anthocyanin aromatic rings with each other and with the IER aromatic matrix [41-43]. The macroporous AV-17-2P resin has larger pores [84] than the AV-17-8 resin, allowing large anthocyanin molecules to penetrate more easily into the AV-17-2P resin and delivering its higher adsorption capacity and the adsorption factor of anthocyanins (Table 1). At $\mathrm{pH} 3$, the AV-17-8 anion-exchange resin adsorbs the least anthocyanins while the KU-2-8 cation-exchange resin (Figure 10a) adsorbs the most. The differences in behavior of these aromatic resins with respect to anthocyanins are mainly determined by the degree of the electrostatic interactions of anthocyanins and fixed groups. Indeed, the KU-2-8 cation-exchange resin equilibrated with the external solution at pH 3 contains Ant ${ }^{+}$cations (Table 3). This cation is the counterion of the negatively charged sulfonic groups of KU-2-8. Thus, the high adsorption capacity of KU-2-8 for anthocyanins is due to at least two types of interactions: (1) the electrostatic interactions between the counterions Ant ${ }^{+}$and sulfonic fixed groups of KU-2-8 and (2) the $\pi-\pi$ (stacking) interactions of the aromatic matrix of the resin with the benzene rings of anthocyanins. Given that the resins AV-17-8 and KU-2-8 have the same aromatic matrix, it can be assumed that the more than $54 \%$ higher adsorption capacity and the coefficient of 
adsorption concentrating of anthocyanins (Table 3) of the cation-exchange resin KU-2-8 are mainly due to the electrostatic interactions (Figure 10a).

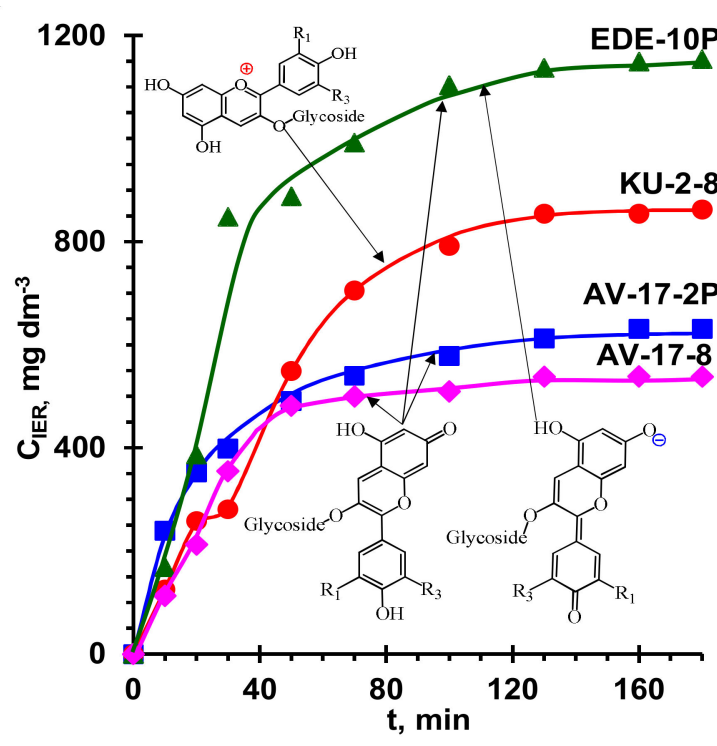

(a)

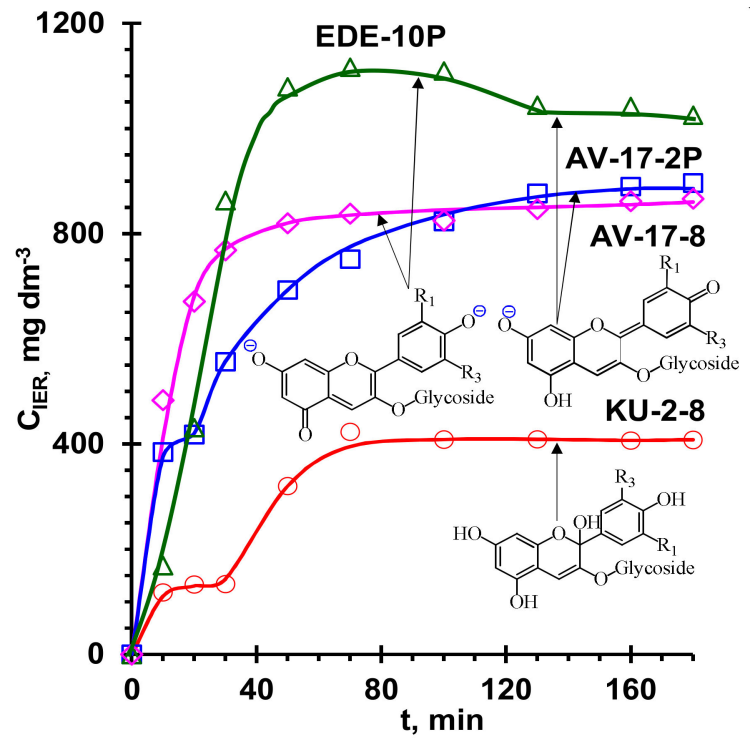

(b)

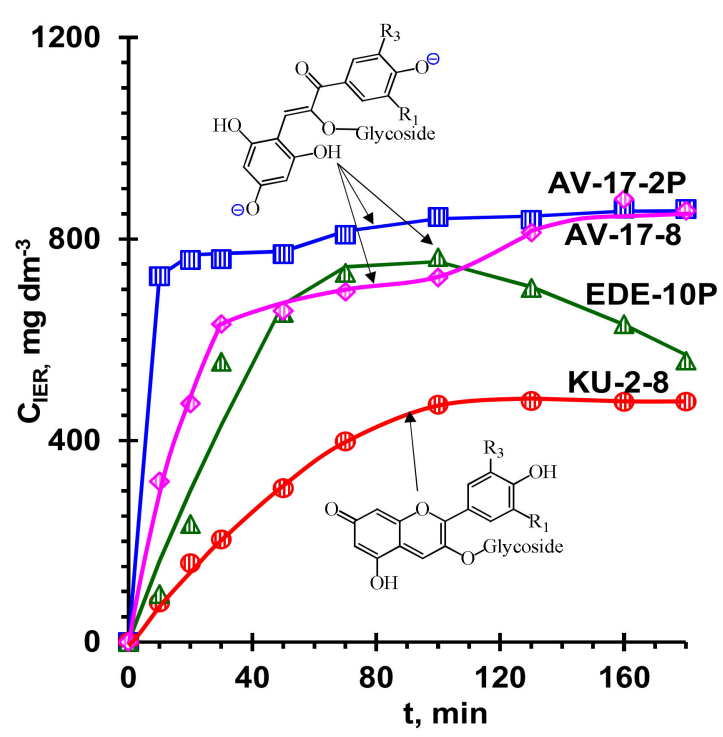

(c)

Figure 10. Kinetics of the anthocyanin adsorption by the ion-exchange resins from the aqueous solutions with initial anthocyanin concentration of $40 \mathrm{mg} \mathrm{dm}^{-3}$ and $\mathrm{pH} 3(\mathbf{a}), 6$ (b), and 9 (c).

When aqueous solutions of anthocyanins have $\mathrm{pH}$ values of 6 , the behavior of the resins changes radically. The adsorption capacity (Figure 10b) of the KU-2-8 cation-exchange resin and the adsorption factor of anthocyanins (Table 1) become respectively 2.1 times less than that of aromatic anion-exchange resin and 2.1 times less than its own adsorption capacity for a solution at $\mathrm{pH} 3$ (Figure 10a). Indeed, in the internal solution of KU-2-8, the $\mathrm{pH}$ is 4 (Table 3), so anthocyanins lose their electrical charge. Therefore, electrostatic interactions of the cation-exchange resin KU-2-8 with $\mathrm{Ant}^{0}$ are absent, and $\pi-\pi$ (stacking) interactions become the main mechanism of their adsorption. On the contrary, when penetrating into AV-17-2P and AV-17-8, anthocyanins acquire a negative charge, $\mathrm{Ant}^{-}$(Table 3), and, in addition to $\pi-\pi$ (stacking) interactions with the ion-exchange matrix, electrostatic interactions take part with the positively charged fixed groups of these anion-exchange resins. Note that the increase in adsorption 
capacity (Figure 10a,b) and absorption factor (Table 3) of anthocyanins during their conversion from $\mathrm{Ant}^{0}$ to $\mathrm{Ant}^{+}(\mathrm{KU}-2-8)$ or $^{-\mathrm{Ant}^{-}}$(AV-17-2P and AV-17-8) increases in the same order as the ion exchange capacity: AV-17-2P $<$ AV-17-8 $<$ KU-2-8.

Finally, if the $\mathrm{pH}$ of the external solution is equal to 9 (Figure 10c), the anthocyanins inside the cation-exchange resin generally remain non-charged molecules (Table 3). Therefore, the kinetic isotherms of the adsorption of anthocyanins by the KU-2-8 resin are close to the curves obtained with the external solution at $\mathrm{pH} 6$ (Figure 10b). Under the same conditions (the external solution at $\mathrm{pH} 9$ ), inside the anion-exchange resins anthocyanins acquire an electrical charge $2^{-}$, Ant ${ }^{2-}$ (Table 3). Nevertheless, the adsorption capacity of these resins (Figure 10c) and the adsorption factor of anthocyanins (Table 3) remain the same as in the case of the neutral $\mathrm{pH}$ values of the external solution (Figure 10b, Table 3). A similar effect was noted by other authors $[42,54,97,98]$ when studying the adsorption of phenols. This effect is probably caused by deprotonation of the weakly basic secondary and tertiary amines in an alkaline medium $[99,100]$. As a result, secondary and tertiary amines that AV-17-8 and AV-17-2P resins contain as impurities [81] no longer participate in electrostatic interactions with negatively charged anthocyanins at high $\mathrm{pH}$ values of the internal solution of these resins (Table 3).

The relatively high content of primary, secondary, and tertiary amines predetermines the peculiarities of the behavior of EDE-10P in comparison with other studied resins. The highest EDE-10P ion-exchange capacity provides the greatest $\mathrm{pH}$ shift to the alkaline range in comparison with AV-17-8 and AV-17-2P resins (Table 3). That is why EDE-10P contains not only Ant ${ }^{0}$ molecules, but also a certain amount of Ant $^{-}$anions (counterions), whereas they are in the form of cations $\mathrm{Ant}^{+}$in the external solution ( $\mathrm{pH}$ 3). This means that electrostatic interactions of anthocyanins with positively charged fixed groups of this resin are not dominant. Moreover, the resin has an aliphatic ion-exchange matrix, which excludes the possibility of its $\pi-\pi$ (stacking) interactions with the aromatic rings of anthocyanins [101]. However, the adsorption capacity (Figure 10a) and the adsorption factor (Table 3) of the EDE-10P are higher than those for aromatic ion exchange resins, in which the $\pi-\pi$ (stacking) interaction (AV-17-8 and AV-17-2P) or $\pi-\pi$ (stacking) and electrostatic interactions (KU-2-8) of anthocyanins are the dominant adsorption mechanisms. This phenomenon is apparently caused by the formation of hydrogen bonds between primary, secondary, and tertiary amines and hydroxyl groups of anthocyanin molecules. The latter type of interaction is more significant in the case of weakly basic fixed groups, which prevail in EDE-10P, compared to quaternary ammonium bases of AV-17-8 and AV-17-2P resins [54,102,103].

Increasing the $\mathrm{pH}$ of the external anthocyanin solution to 6 and 9 increases the $\mathrm{pH}$ of EDE-10P internal solutions to 11 and 12 (Table 3). Consequently, the fraction of $\mathrm{Ant}^{2-}$ anions increased in this resin. At the same time, the fraction of deprotonated weakly basic fixed groups grew, reducing the ability of these groups to participate in hydrogen bonds and electrostatic interactions with anthocyanins. The combined effect of both phenomena leads to a noticeable decrease in the adsorption capacity of EDE-10P when the $\mathrm{pH}$ of the external solutions was at 6 (Figure 10b) and especially at 9 (Figure 10c). In the case of $\mathrm{pH} 9$, the negative effect of deprotonation of weakly basic fixed groups is so great that the adsorption capacity (Figure 10c) and the adsorption factor (Table 3) of the EDE-10P resin become close to KU-2-8, which do not enter into electrostatic interactions with $\mathrm{Ant}^{0}$ molecules and $\mathrm{Ant}^{-}$anions. The maximum on the adsorption isotherms of EDE-10P (Figure 10b,c) is apparently caused by the fact that the processes of deprotonation of fixed groups, destruction of hydrogen bonds, and diffusion of "released" anthocyanins from the resin back into the external solution take time.

These results clarify some of the discussion points mentioned in the Introduction. In particular, this is an equally high adsorption of phenols and polyphenols by strong basic anion exchange materials from neutral and alkaline solutions, which were observed despite the fact that in these external solutions they are uncharged molecules and anions, respectively $[42,54,97,98]$. The key moment to explain this phenomenon is the $\mathrm{pH}$ shift of the internal solution of anion-exchange materials to the alkaline range due to the Donnan exclusion of protons-the products of the protonation-deprotonation reactions. Thus, in a neutral external solution, these substances are uncharged molecules, but getting into the 
anion-exchange resin, they become anions. This provides electrostatic interactions with the resin at the same level as in the case of alkaline external solution in which phenol and polyphenols are initially in the deprotonated state. These results are important for the practice of extracting anthocyanins, because they justify the use of anion exchange resins under conditions in which anthocyanins retain a higher biological activity $[104,105]$.

As to cation-exchange resins, the well-known fact is confirmed: acidification of the external solution enhances the adsorption of anthocyanins due to the significant increase in electrostatic interactions.

\subsection{Effect of the Concentration of Anthocyanins in External Solutions on Their Adsorption by Resins}

Figure 11 shows the kinetic dependences of the adsorption of anthocyanins by aromatic resins, which demonstrated the maximum (KU-2-8) and minimum (AV-17-8) adsorption capacity in the case of a solution of anthocyanins with $\mathrm{pH} 3$. These curves were obtained for the concentrations of anthocyanins in an initial external solution ( $\mathrm{pH}$ 3) from 10 to $100 \mathrm{mg} \mathrm{dm}^{-3}$ and used to obtain equilibrium adsorption isotherms indicated by the sub-index $\mathrm{E}$ (Figure 12). The results of processing these isotherms using Langmuir, Freundlich, and Brunauer-Emmett-Teller (BET) models [106,107] and linear regression methods (Section 3.3.4.) are summarized in Table 4.

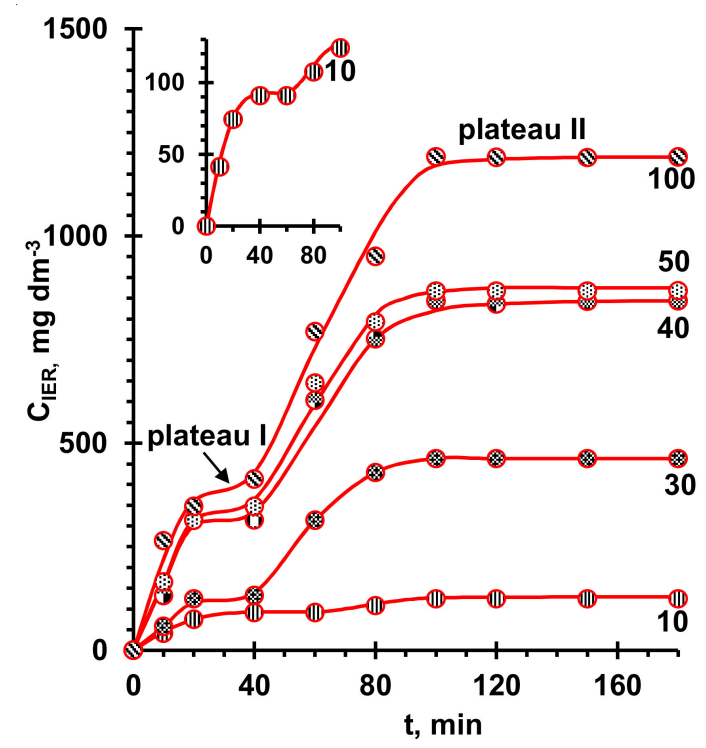

(a)

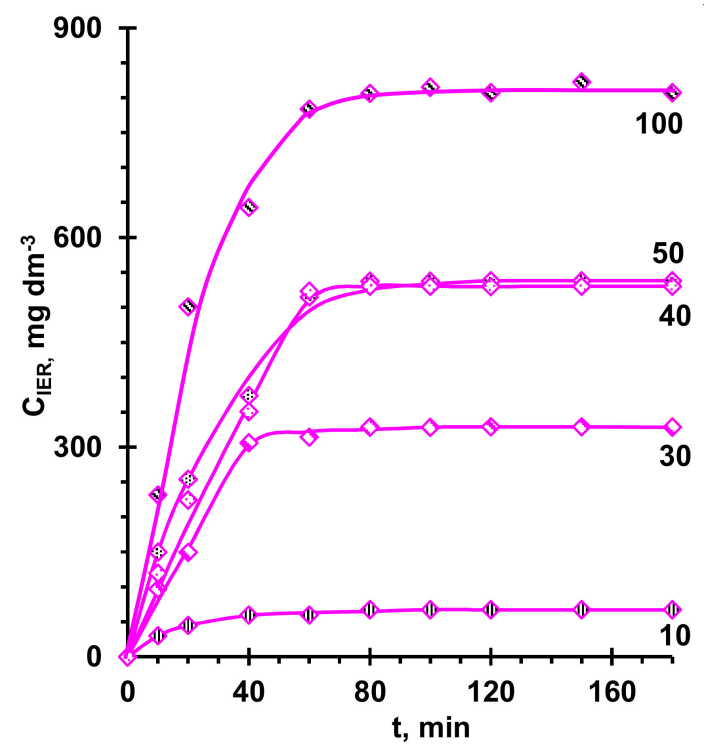

(b)

Figure 11. Kinetics of the anthocyanins adsorption by KU-2-8 (a) and AV-17-8 (b) ion-exchange resins from aqueous solutions with $\mathrm{pH} 3$. The numbers near the curves indicate the concentration of anthocyanins in the solution, $C_{S O}\left(\mathrm{mg} \mathrm{dm}^{-3}\right)$.

Table 4. Fitting results of experimental equilibrium isotherms using equations of Langmuir, Freundlich, and Brunauer-Emmett-Teller (BET) models (Section 3.3.4).

\begin{tabular}{|c|c|c|c|c|c|c|c|c|}
\hline & \multicolumn{4}{|c|}{ KU-2-8 } & \multicolumn{4}{|c|}{ AB-17-8 } \\
\hline & 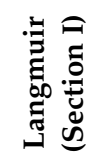 & 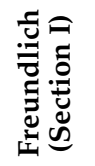 & 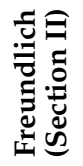 & 鼻 & 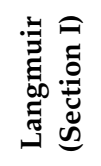 & 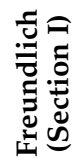 & 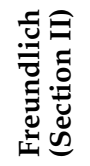 & $\stackrel{-1}{\stackrel{1}{n}}$ \\
\hline$R^{2}$ & 0.947 & 0.998 & 0.982 & 0.884 & 0.922 & 0.961 & 0.982 & 0.844 \\
\hline$q_{m}\left(\mathrm{mg} \mathrm{g}_{\mathrm{dry}}{ }^{-1}\right)$ & -0.930 & - & & 1.550 & -0.251 & - & & 0.850 \\
\hline$K_{L}\left(\mathrm{mg} \mathrm{dm}^{-3}\right)^{-1}$ & -0.040 & - & & - & -0.050 & - & & - \\
\hline$K_{F}\left(\mathrm{mg} \mathrm{dm}^{-3}\right)^{-1}$ & - & 0.002 & 0.420 & - & - & 0.003 & 0.154 & - \\
\hline$K_{s}\left(\mathrm{mg} \mathrm{dm}^{-3}\right)^{-1}$ & - & - & & 0.110 & - & - & & 0.067 \\
\hline$K_{B}\left(\mathrm{mg} \mathrm{dm}^{-3}\right)^{-1}$ & - & - & & 0.008 & - & - & & 0.008 \\
\hline
\end{tabular}




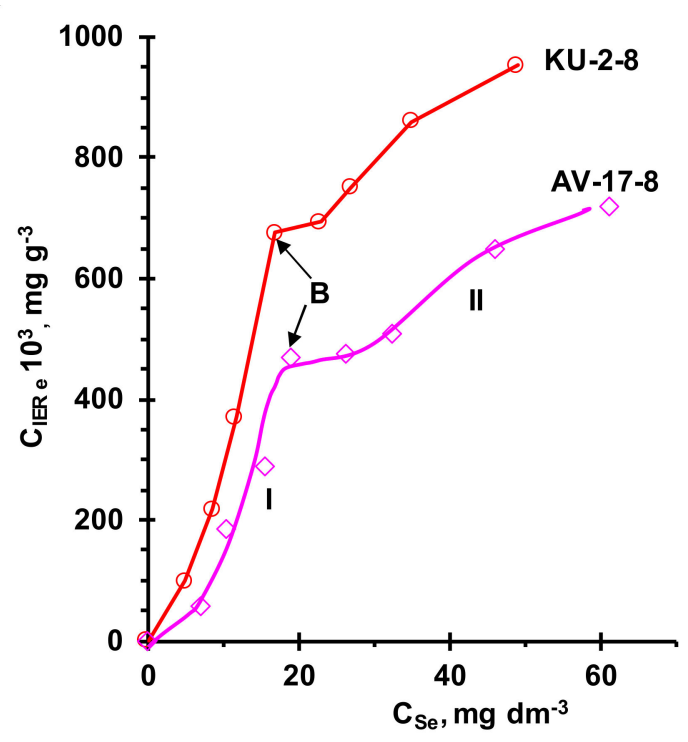

(a)

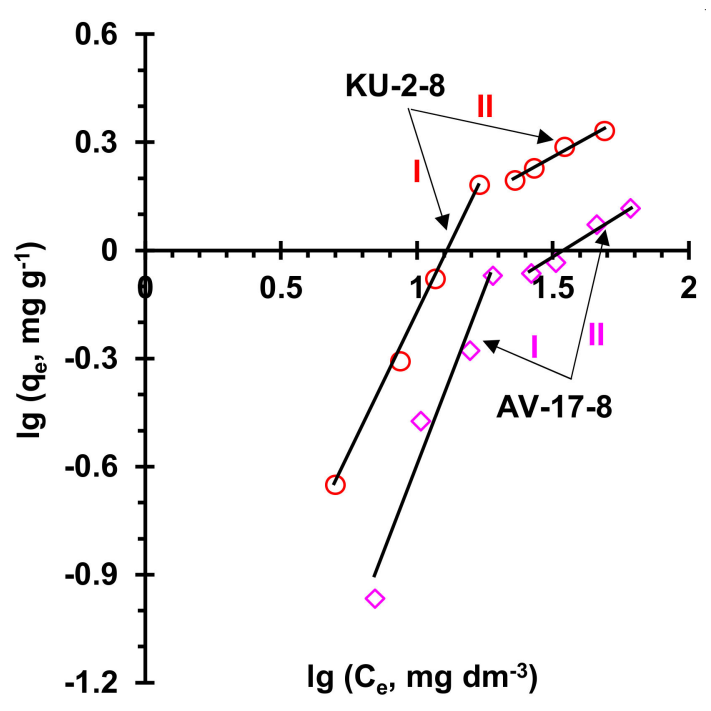

(b)

Figure 12. Equilibrium isotherms of anthocyanins adsorption (a) by resins KU-2-8 and AV-17-8 from anthocyanins solutions at $\mathrm{pH} 3$ and the same isotherms processed using the Freundlich equation (Section 3.3.4.) (b). Point B corresponds to the transition from monomolecular to polymolecular adsorption.

Attention should be paid to the fact that the kinetic isotherms of adsorption of the cation exchange resin KU-2-8 from a solution at $\mathrm{pH} 3$ have two distinct plateaus (Figure 11a). However, plateau I becomes less and less noticeable with an increase in external solution $\mathrm{pH}$ (Figure 10c), that is, under conditions when anthocyanin cations become uncharged molecules. The presence of two plateaus when anthocyanins in the resin are cations suggests that at the beginning, the adsorption of anthocyanins occurs mainly due to weak $\pi-\pi$ (stacking) interactions with the KU-2-8 aromatic matrix. Diffusion of large species of anthocyanins into the resin, their participation in protonation-deprotonation reactions, and reverse diffusion of protolysis products take from $60\left(C_{S 0}=10 \mathrm{mg} \mathrm{dm}^{-3}\right)$ to $30\left(C_{S 0}=100 \mathrm{mg} \mathrm{dm}^{-3}\right)$ minutes. A further increase in the concentration of adsorbate in KU-2-8 is mainly provided by electrostatic interactions of anthocyanin counterions with fixed resin groups. The ratio $C_{I E R}{ }^{I I} / C_{I E R}{ }^{I}$, where $C_{I E R}{ }^{I}$ and $C_{I E R}{ }^{I I}$ are the anthocyanin concentrations in the resin, determined from plateaus I and II, gives an idea of the contribution of these electrostatic interactions to the total adsorption capacity of the cation exchange resin. The ratio is equal to $1.4\left(C_{S 0}=10 \mathrm{mg} \mathrm{dm}^{-3}\right), 2.8\left(C_{S 0}=50 \mathrm{mg} \mathrm{dm}^{-3}\right)$, and $3.4\left(C_{S 0}=100 \mathrm{mg} \mathrm{dm}^{-3}\right)$, and, as reported in references [33,50,102], increases with increasing anthocyanin concentration in the solution. This growth is apparently caused by phenomena coupled with electrostatic interactions, which require further study.

In the case of the AV-17-8 anion-exchange resin, a weakly expressed plateau I is recorded for neutral and alkaline external solutions (Figure 10b,c), when anthocyanins inside the resin acquire a negative electric charge (Table 3 ) and become counterions for resin positively charged fixed groups. On the contrary, there is no plateau I if the external solution has a $\mathrm{pH}$ of 3 (Figure 11b) since the anthocyanins inside the resin lose their electrical charge. Apparently, in this case, the formation of hydrogen bonds and other interactions between the hydroxyl groups of anthocyanins and the ammonium groups of AV-17-8 partially compensate the electrostatic adsorbent-adsorbate interactions. It can be assumed that the intra-diffusion kinetics limit this type of interaction to a much lesser extent. This predetermines the weak manifestation of plateau I on the kinetic curves of adsorption even in the case when $\pi-\pi$ (stacking) interactions and the formation of hydrogen bonds are supplemented by electrostatic adsorbent-adsorbate interactions. 
Both equilibrium isotherms (Figure 12) have borderline shape between the type $\mathrm{V}$ and VI isotherms; concave initial sections correspond to isotherm type III according to the IUPAC classification [108]. Such a concave type of isotherm generally corresponds to adsorption with relatively weak adsorbent-adsorbate interactions. It is believed that this weakness causes a small capacity at the beginning, but if at least one molecule is adsorbed, adsorbate-adsorbate interactions further enhance adsorption of other molecules. Indeed, this initial section I (up to point B) of equilibrium isotherms is best described using the Freundlich model, which characterizes adsorption with a non-uniform distribution of adsorption affinities over adsorbent surface [109]. The values of the adsorption constants found using the Freundlich equation (Table 4) are in good agreement with studies on the adsorption of various polyphenols by ion-exchange resins. These studies are summarized, for example, in reviews $[15,109]$. The Langmuir equation, used to describe section I, gives a noticeably lower value of the coefficient of determination, $R^{2}$ (Table 4); moreover, the found amount of adsorbate corresponding to complete monolayer adsorption, $q_{m}$, and the Langmuir isotherm constant, $K_{L}$, have negative values; that is, they have no physical meaning. This result is expected because this model takes into account monolayer adsorption that only occurs at fixed identical and equivalent sites with no lateral interactions or steric hindrance between an adsorbent and adsorbate.

Point B on the "knee" of equilibrium isotherms characterizes the transition from monomolecular to polymolecular adsorption (section II). An indirect confirmation of the polymolecular adsorption of anthocyanins is the identification of dimers and trimers of these substances in ion-exchange membranes [110] that had a chemical structure similar to the studied resins and put in contact with anthocyanin-containing solutions. Among the reasons for such polymolecular adsorption are the $\pi-\pi$ (stacking) interaction of the aromatic rings of polyphenols with each other $[29,50]$ or with substances with the opposite electric charge at a given $\mathrm{pH}$ [111]. We assume that in our case the main reason for polymolecular adsorption is the $\pi-\pi$ (stacking) interactions between already adsorbed anthocyanins and those in the pores of the resin or in the external solution. Really, the external anthocyanin solution does not contain polyphenols (Table 1). In addition, the pores of the studied resins (and membranes [100]) are too small for the penetration of polyphenols.

Processing section II of adsorption isotherms using the Freundlich model gives a high coefficient of determination and allows us to conclude that the adsorption constants increase by a two order of magnitude if the equilibrium concentration of anthocyanins in the external solution becomes greater than $30 \mathrm{mg} \mathrm{dm}^{-3}$. At the same time, the BET model, which is most often used to describe the polymolecular adsorption of phenols $[50,112,113]$ and polyphenols $[65,114]$ by ion-exchange resins, gives a rather low coefficient of determination values (Table 2). The use of other (Frenkel-Halsey-Hill, MacMillan-Teller) models of polymolecular adsorption [109] known to us also does not give satisfactory results. Apparently, this is caused by the too complex nature of the interactions between anthocyanins and the studied ion-exchange resins.

\section{Materials and Methods}

\subsection{Ion-Exchange Resins}

Prior to experiments, the resins were immersed in a saturated $\left(300 \mathrm{~g} \mathrm{dm}^{-3}\right) \mathrm{NaCl}$ solution for $24 \mathrm{~h}$ and then rinsed with small volumes of deionized water. The rinsing was completed when the electrical conductivity and $\mathrm{pH}$ of water, equilibrated with the resin for one hour, differed from less than $5 \%$ from that of initial deionized water.

\subsection{Solutions}

In experiments, we used a natural dye-anthocyanin — which was purchased from Frutarom Etol d.o.o. (Škofja Vas, Slovenia).

A colorimetric scale of aqueous $\left(40 \mathrm{mg} \mathrm{dm}^{-3}\right)$ solutions of anthocyanins in the $\mathrm{pH} 1$ to 12 range was obtained using the buffer solutions listed in Table 5 . 
Table 5. Composition of buffer solutions used to prepare colorimetric scales of anthocyanins.

\begin{tabular}{|c|c|}
\hline Buffer Solution & $\mathrm{pH}$ \\
\hline $\begin{array}{l}\text { Potassium chloride }\left(0.05 \mathrm{~mol} \mathrm{~kg}^{-1}\right)+\text { hydrochloric } \\
\text { acid }\left(0.097 \mathrm{~mol} \mathrm{~kg}^{-1}\right)\end{array}$ & 1.01 \\
\hline Potassium tetraoxalate dihydrate $\left(0.05 \mathrm{~mol} \mathrm{~kg}^{-1}\right)$ & 1.65 \\
\hline Potassium hydrogen tartrate $\left(0.05 \mathrm{~mol} \mathrm{~kg}^{-1}\right)$ & 3.56 \\
\hline Potassium hydrogen phthalate $(0.05 \mathrm{~mol} \mathrm{~kg}-1)$ & 4.01 \\
\hline $\begin{array}{l}\text { Potassium dihydrogen phosphate }\left(0.26 \mathrm{~mol} \mathrm{~kg}^{-1}\right)+ \\
\text { Disodium hydrogen phosphate }\left(0.04 \mathrm{~mol} \mathrm{~kg}^{-1}\right)\end{array}$ & 7.00 \\
\hline Sodium tetraborate decahydrate $\left(0.01 \mathrm{~mol} \mathrm{~kg}^{-1}\right)$ & 9.18 \\
\hline $\begin{array}{l}\text { Sodium carbonate }\left(0.025 \mathrm{~mol} \mathrm{~kg}^{-1}\right)+\text { sodium } \\
\text { hydrogen carbonate }\left(0.025 \mathrm{~mol} \mathrm{~kg}^{-1}\right)\end{array}$ & 10.01 \\
\hline $\begin{array}{l}\text { Sodium carbonate }\left(0.05 \mathrm{~mol} \mathrm{~kg}^{-1}\right)+ \\
\text { sodium tetraborate decahydrate }\left(0.00135 \mathrm{~mol} \mathrm{~kg}^{-1}\right)\end{array}$ & 11.00 \\
\hline $\begin{array}{l}\text { Potassium chloride }\left(0.05 \mathrm{~mol} \mathrm{~kg}^{-1}\right)+\text { sodium } \\
\text { hydroxide }\left(0.012 \mathrm{~mol} \mathrm{~kg}^{-1}\right)\end{array}$ & 12.00 \\
\hline
\end{tabular}

All reagents (CJSC «Vekton», Saint Petersburg, Russia) were of analytical grade. Deionized water with an electrical conductivity of $1.5 \mu \mathrm{S} \mathrm{cm}{ }^{-1}$ and a $\mathrm{pH}$ of 5.5 was used for all the experiments.

\subsection{Methods}

\subsubsection{The pH Differential Spectrophotometric Method}

The $\mathrm{pH}$ differential method [34,115] using a LEKI SS 2107 spectrophotometer (Leki Instruments, Finland) was applied to determine the total concentration of anthocyanins in solution. Two $0.5 \mathrm{~cm}^{3}$ samples were taken from the solution and their volume increased to $10 \mathrm{~cm}^{3}$ by adding $\mathrm{pH} 1$ or 4.5 buffer solutions. After 15 minutes, the optical density of the resulting solutions was determined at wavelengths of 520 and $700 \mathrm{~nm}$. The optical density, $A$, of anthocyanins was calculated using the equation: $A=\left(A_{520}-A_{700}\right)_{\mathrm{pH} 1}-\left(A_{520}-A_{700}\right)_{\mathrm{pH} 4.5}$. The total concentration of anthocyanins in the solution, $C_{s}\left(\mathrm{mg} \mathrm{dm}^{-3}\right)$, was expressed as equivalent of cyanidin-3-glucoside using the following expression:

$$
C_{S}=\frac{A M V_{1}}{V_{2} \varepsilon l} \times 10^{3},
$$

where $M$ is the molecular weight of cyanidin-3-glucoside $\left(449.2 \mathrm{~g} \mathrm{~mol}^{-1}\right) ; V_{1}$ is the volume of the volumetric flask used to dilute the sample $\left(\mathrm{cm}^{3}\right) ; V_{2}$ is the sample volume taken for analysis, $\left(\mathrm{cm}^{3}\right) ; \varepsilon$ is the molar extinction coefficient of cyanidin-3-glucoside $\left(26,900\left[\mathrm{~mol} \mathrm{~cm} \mathrm{dm}^{-3}\right]^{-1}\right)$; and $l$ is the optical path length of a cuvette $(1 \mathrm{~cm})$.

\subsubsection{High-Performance Liquid Chromatography (HPLC) Analysis}

The composition of the anthocyanins extract from grape pulp used in the experiments was determined by HPLC [116] using the Agilent 1100 HPLC system (Agilent Technologies, Santa Clara, CA, USA) and a Luna $2 \times 250$ mm C18 column (Phenomenex, Torrance, CA, USA).

\subsubsection{Fourier Transform Infrared (FTIR) Spectroscopy and Optic Analysis}

Two methods were used to determine the structures of anthocyanins in the solutions and resins. FTIR spectra were obtained using a Vertex-70 (Bruker Optics, Germany) and the ATR (attenuated total reflection) accessory in the wavelength range of $4000-400 \mathrm{~cm}^{-1}$ with $4 \mathrm{~cm}^{-1}$ spectral resolution and 32 scans. The intensity of the spectra was normalized by subtracting the recorded baseline using OPUS ${ }^{\mathrm{TM}}$ software. Prior to measurements, the solutions of anthocyanins were dried out by evaporating the moisture at $40{ }^{\circ} \mathrm{C}$. The resin samples were equilibrated with the external solutions of anthocyanins at the given $\mathrm{pH}$ values. After that, the IERs were removed from the solutions, ground, and dried to constant weight at $50^{\circ} \mathrm{C}$. 
In addition to the information provided by the IR spectra, the structures of anthocyanins adsorbed by the IER were assessed by comparing the colors of the resin using the colorimetric scale of the anthocyanin solutions. This scale was obtained using buffer solutions (Table 5) with $\mathrm{pH}$ values from 1 to 12 and the known data on the conversion of their structure as a function of $\mathrm{pH}$ [1] (Figure 1). Optical images of the anthocyanin solutions and IERs before and after their contact with the anthocyanin solutions were obtained at constant luminous intensity (ensured by the constant electric power $14 \mathrm{~W} \pm 5 \%$ consumed by the light source) and an optical path length of $225 \mathrm{~mm}$ using a SOPTOP CX40M optical microscope (China) with a set of $5 \times$ objective and a digital eyepiece camera.

\subsubsection{Kinetics and Equilibrium Isotherms of the Anthocyanins Adsorption}

The kinetics of the anthocyanins' adsorption by the ion-exchange resins were determined using the constant volume method. Samples of the swollen ion-exchange resin weighing $1.0 \pm 0.01 \mathrm{~g}$ were placed in 10 flasks with ground stoppers. A standard volume $\left(20 \mathrm{~cm}^{3}\right)$ of the anthocyanin solution of a given concentration and $\mathrm{pH}$ was added and the mixture was shaken at $80 \mathrm{~min}^{-1}$ frequency using an EcoPribor PE-0034 shaker. Samples $\left(0.5 \mathrm{~cm}^{3}\right)$ from each flask were taken after a predetermined time (from 10 to $180 \mathrm{~min}$ ) to determine the concentration of anthocyanins and the $\mathrm{pH}$ of the solution after contact with the resin.

The total concentration of anthocyanins in an ion-exchange resin $\left(\mathrm{mg} \mathrm{g}^{-1}\right)$ was determined using the following equation:

$$
C_{I E R}=\frac{\left(C_{S 0}-C_{S t}\right) V_{s}}{V_{I E R}}
$$

where $C_{S 0}$ and $C_{S t}$ are total concentrations of anthocyanins in the initial and predetermined time interval of contact of the external solution with the resin $\left(\mathrm{mg} \mathrm{g}^{-1}\right) ; V_{I E R}=m / \rho$ is the volume $\left(\mathrm{cm}^{3}\right)$; $m$ and $\rho$ are the mass $(\mathrm{g})$ and true density $\left(\mathrm{g} \mathrm{cm}^{-3}\right)$ of the swollen resin, respectively; and $V_{s}$ is the volume of solution in contact with the resin $\left(\mathrm{in}^{3}\right.$ ). All experiments were carried out under isothermal conditions at a temperature of $25 \pm 1{ }^{\circ} \mathrm{C}$.

In this study, Langmuir, Freundlich, and Brunauer-Emmett-Teller (BET) models [106,107] were used to describe the adsorption equilibrium between the liquid phase and the adsorbent. Isotherm equations of these models are presented in Table 6.

Table 6. Lists of adsorption isotherms models under study.

\begin{tabular}{ccc}
\hline Model & Non-Linear Form & Linear Form \\
\hline Langmuir & $q_{e}=\frac{q_{m} K_{L} C_{e}}{1+K_{L} C_{e}}$ & $\frac{1}{q_{e}}=\frac{1}{q_{m} K_{L}}\left(\frac{1}{C_{e}}\right)+\frac{1}{q_{m}}$ \\
Freundlich & $q_{e}=K_{F} C_{e}^{\frac{1}{n}}$ & $\log q_{e}=\log K_{F}+(1 / n)\left(\log C_{e}\right)$ \\
BET & $q_{e}=\frac{q_{m} K_{S} C_{e}}{\left(1-K_{B} C_{e}\right)\left(1-K_{B} C_{e}+K_{S} C_{e}\right)}$ & $\frac{C_{e}}{q_{e}\left(1-K_{B} C_{e}\right)}=\frac{1}{q_{m} K_{B}}+\frac{C_{e}\left(K_{B}-K_{S}\right)}{q_{m} K_{B}}$
\end{tabular}

where $q_{e}\left(\mathrm{mg} \mathrm{g}^{-1}\right)$ is the amount of adsorbate adsorbed on the solid surface at equilibrium concentration $C_{e}\left(\mathrm{mg} \mathrm{dm}^{-3}\right)$ and $q_{m}\left(\mathrm{mg} \mathrm{g}^{-1}\right)$ is the amount of adsorbate corresponding to complete monolayer adsorption. $K_{F}\left(\mathrm{mg} \mathrm{dm}^{-3}\right)^{-1}$ and $n$ are Freundlich constants representing the Freundlich isotherm constant. $K_{L}\left(\mathrm{mg} \mathrm{dm}^{-3}\right)^{-1}$ represents the Langmuir isotherm constant and $K_{s}, K_{B}\left(\mathrm{mg} \mathrm{dm}^{-3}\right)^{-1}$ are the equilibrium constants of adsorption for 1st and upper layers in BET isotherm, respectively.

\section{Conclusions}

The focus of this study was to characterize mechanisms of anthocyanin adsorption by ion-exchange resins from model aqueous anthocyanin-containing solutions at different $\mathrm{pH}$ values.

Using optical color indication and IR spectroscopy, it is shown that the $\mathrm{pH}$ of the internal solution is 2-3 units lower in the case of an aromatic cation-exchange resin KU-2-8, and 2-4 units higher in the case of anion-exchange resins with aromatic (AV-17-8, AV-17-2P) and aliphatic (EDE-10P) matrix compared to the $\mathrm{pH}$ of the external anthocyanin solution. This effect is caused by Donnan exclusion of hydroxyl ions (KU-2-8) or protons (AV-17-8, AV-17-2P, EDE-10P), which are products of anthocyanins 
protolysis reactions. The Donnan exclusion increases with the increasing ion-exchange capacity of the resin. Thus, the most noticeable $\mathrm{pH}$ shift was observed in the EDE-10P resin, which had the highest ion-exchange capacity.

In the external solutions with $\mathrm{pH} 3,6$, and 9, anthocyanins are cations, uncharged molecules, and singly charged anions, respectively. Due to the shift in $\mathrm{pH}$, the electrical charge of anthocyanins inside the ion exchange resins differs from their charge in the external solution. As a result, in KU-2-8 internal solution anthocyanins remain cations ( $\mathrm{pH} 3$ external solution) or become uncharged molecules (pH 6 and 9 external solutions). In the AV-17-8 and AV-17-2P internal solutions, they become uncharged molecules ( $\mathrm{pH} 3$ external solution), singly charged ( $\mathrm{pH} 6$ external solution), or doubly charged ( $\mathrm{pH} 9$ external solution) anions. If anthocyanins inside the resin are counterions, their electrostatic interactions with fixed groups essentially strengthen the adsorption caused by $\pi-\pi$ (stacking) interactions of the aromatic rings of the adsorbate and the adsorbent. Our estimates show that in the case of KU-2-8 ( $\mathrm{pH} 3$ external solution), electrostatic interactions increase the maximum adsorption capacity of the resin by 1.4-3.4 times compared with that which can be achieved due to $\pi-\pi$ (stacking) and other possible interactions. In the investigated range of anthocyanin concentrations in the external solution (from 10 to $100 \mathrm{mg} \mathrm{dm}^{-3}$ ), the contribution of electrostatic interactions to the adsorption capacity of the resin depends on the contact time of the IER with the external solution and increases with an increase in the adsorbate concentration in it.

At a given concentration of anthocyanins in an external solution $\left(40 \mathrm{mg} \mathrm{dm}^{-3}\right)$, the maximum adsorption capacity of KU-2-8 in an acidic external solution increases by 2 times compared to neutral and alkaline solutions. In the case of the anion-exchange resins AV-17-8 and AV-17-2P, the adsorption capacity increases by only 1.4 and 1.5 times when passing from acidic to neutral and alkaline external solutions. The decrease in the effect of electrostatic interactions of the adsorbent-adsorbate in comparison with the cation-exchange resin, apparently, is caused by the partial deprotonation of weakly basic fixed groups of anion-exchange resins when the internal solution is strongly alkaline ( $\mathrm{pH} 11-12)$. This deprotonation is tantamount to a partial loss of the resin's ion exchange capacity.

The aliphatic resin EDE-10P, when in an external solution at $\mathrm{pH} 3$, contains a mixture of anions and uncharged anthocyanin molecules. The high adsorption capacity of this resin, which exceeds the one observed in the case of KU-2-8, is apparently due to a combination of electrostatic interactions between the adsorbate and the adsorbent, as well as the formation of a large number of hydrogen bonds between the hydroxyl groups of anthocyanins and EDE-10P primary, secondary, and tertiary amines. Deprotonation of these groups in a highly alkaline medium of the internal solution $(\mathrm{pH} 6$ or 9 external solution) negates the gain from the conversion of anthocyanins into doubly charged anions-counterions. As a result, the maximum adsorption capacity of EDE-10P is observed in the case of a weakly acidic external solution ( $\mathrm{pH} 3)$.

Polymolecular adsorption in the systems under study is clearly manifested if the concentration of anthocyanins in the external equilibrium solution exceeds $30 \mathrm{mg} \mathrm{dm}^{-3}$.

The knowledge gained in this study not only expands our understanding of the adsorption mechanisms of anthocyanins by aromatic and aliphatic IERs but also has practical value. Indeed, to ensure the maximum adsorption capacity of anion-exchange resins, it is better to not use alkaline (as it is often practiced), but neutral or even slightly acidic aqueous solutions of anthocyanins. This conclusion is also important because in an alkaline environment, anthocyanins can undergo partial destruction and lose their biological activity $[107,108]$. This new knowledge can also help to develop the strategies of resins and membrane cleaning as well as the strategies for extracting anthocyanins from wine and juice waste using ion-exchange resins and membranes.

Author Contributions: Conceptualization, L.B. and N.P.; methodology, N.P.; validation, V.S.; formal analysis, V.N.; investigation, S.M., V.S. and A.K.; data curation, N.P.; writing-Original draft preparation, N.P. and L.B.; writing-Review and editing, N.P.; visualization, V.S.; supervision, L.B. and N.P.; project administration, N.P. and L.B.; funding acquisition, N.P. and L.B. All authors have read and agreed to the published version of the manuscript. 
Funding: This work was financially supported by the Russian Foundation for Basic Research, project No 19-48-230024 reg_a (study of the anthocyanin conversion inside IERs) and the Natural Sciences and Engineering Research Council of Canada (NSERC) Project IRCPJ 492889-15 (NSERC Industrial Research Chair on ElectroMembrane processes aiming the ecoefficiency improvement of biofood production lines) and project SD RGPIN-2018-04128 (improvement of electrodialytic processes performances for biofood applications using innovative electric current conditions).

Conflicts of Interest: The authors declare no conflict of interest.

\section{Abbreviations}

A

AER

Ant

BET

ATR-FTIR

CER

$\mathrm{C}_{e}$

$\mathrm{C}_{S}$

$\mathrm{C}_{\mathrm{SO}}$

$C_{S t}$

$C_{\text {IER }}$

DVB

$\mathrm{ECH}$

IER

HPLC

$K_{a}$

$K_{F}$

$K_{L}$

$l$

m

M

$n$

PEPAs

PS

$q_{m}$

$q_{e}$

$V_{\text {IER }}$

$\mathrm{V}_{1}$

$\mathrm{V}_{\mathrm{S}}$

$\varepsilon$

$\rho$
Optical density

Anion-exchange resins

Anthocyanin

Brunauer-Emmett-Teller

Attenuated total reflection-Fourier transform infrared spectroscopy

Cation-exchange resins

Equilibrium concentration of anthocyanins in the solution, $\left(\mathrm{mg} \mathrm{dm}^{-3}\right)$

Total concentration of anthocyanins in the solution, $\left(\mathrm{mg} \mathrm{dm}^{-3}\right)$

Total initial concentrations of anthocyanins in the external solution, $\left(\mathrm{mg} \mathrm{dm}^{-3}\right)$

Total concentrations of anthocyanins at time $t$ of contact of the external solution with the resin, $\left(\mathrm{mg} \mathrm{g}^{-1}\right)$

Total concentration of anthocyanins in an ion-exchange resin, $\left(\mathrm{mg} \mathrm{g}^{-1}\right)$

Divinylbenzene

Epichlorohydrin

Ion-exchange resin

High-performance liquid chromatography

Dissociation constant

Equilibrium constant of adsorption in Freundlich isotherm, $\left(\mathrm{mg} \mathrm{dm}^{-3}\right)^{-1}$

Equilibrium constant of adsorption in Langmuir isotherm, $\left(\mathrm{mg} \mathrm{dm}^{-3}\right)^{-1}$

Optical path length of a cuvette, $(1 \mathrm{~cm})$

Mass of the swollen resin, $(\mathrm{g})$

Molecular weight of cyanidin-3-glucoside, $\left(449.2 \mathrm{~g} \mathrm{~mol}^{-1}\right)$

Adsorption intensity

Polyethylene polyamines

Polystyrene

Amount of adsorbate corresponding to complete monolayer adsorption, $\left(\mathrm{mg} \mathrm{g}^{-1}\right)$

Amount of adsorbate adsorbed on the solid surface at equilibrium concentration,

$\left(\mathrm{mg} \mathrm{g}^{-1}\right)$

Volume of the swollen resin, $\left(\mathrm{cm}^{3}\right)$

Volume of the volumetric flask used to dilute the sample, $\left(\mathrm{cm}^{3}\right)$

Volume of solution in contact with the resin, $\left(\mathrm{cm}^{3}\right)$

Molar extinction coefficient of cyanidin-3-glucoside, $\left(26,900\left[\mathrm{~mol} \mathrm{~cm} \mathrm{dm}^{-3}\right]^{-1}\right)$

Density of the swollen resin, $\left(\mathrm{g} \mathrm{cm}^{-3}\right)$

\section{References}

1. Ribéreau-Gayon, P.; Glories, Y.; Maujean, A.; Dubourdieu, D. Handbook of Enology: The Chemistry of Wine, Stabilization and Treatments, 2nd ed.; John Wiley \& Sons Ltd: Chichester, UK, 2006; ISBN 978-0-470-01037-2.

2. Coklar, H.; Akbulut, M. Anthocyanins and phenolic compounds of Mahonia aquifolium berries and their contributions to antioxidant activity. J. Funct. Foods 2017, 35, 166-174. [CrossRef]

3. Raffa, D.; Maggio, B.; Raimondi, M.V.; Plescia, F.; Daidone, G. Recent discoveries of anticancer flavonoids. Eur. J. Med. Chem. 2017, 142, 213-228. [CrossRef] [PubMed]

4. Ma, L.; Sun, Z.; Zeng, Y.; Luo, M.; Yang, J. Molecular Mechanism and Health Role of Functional Ingredients in Blueberry for Chronic Disease in Human Beings. Int. J. Mol. Sci. 2018, 19, 2785. [CrossRef] 
5. Nielsen, I.L.F.; Dragsted, L.O.; Ravn-Haren, G.; Freese, R.; Rasmussen, S.E. Absorption and Excretion of Black Currant Anthocyanins in Humans and Watanabe Heritable Hyperlipidemic Rabbits. J. Agric. Food Chem. 2003, 51, 2813-2820. [CrossRef] [PubMed]

6. Winter, A.N.; Bickford, P.C. Anthocyanins and Their Metabolites as Therapeutic Agents for Neurodegenerative Disease. Antioxidants 2019, 8, 333. [CrossRef] [PubMed]

7. Rodriguez-Amaya, D.B. Natural food pigments and colorants. Curr. Opin. Food Sci. 2016, 7, 20-26. [CrossRef]

8. Kumar, A.V.; Raj, A.; Lakshmi, A.; Ojha, N.; Das, N. A green approach towards utilization of Floral wastes for the extraction of Natural Colorants. Res. J. Pharm. Technol. 2019, 12, 269. [CrossRef]

9. Choi, I.; Lee, J.Y.; Lacroix, M.; Han, J. Intelligent $\mathrm{pH}$ indicator film composed of agar/potato starch and anthocyanin extracts from purple sweet potato. Food Chem. 2017, 218, 122-128. [CrossRef]

10. Galvano, F.; La Fauci, L.; Lazzarino, G.; Fogliano, V.; Ritieni, A.; Ciappellano, S.; Battistini, N.C.; Tavazzi, B.; Galvano, G. Cyanidins: Metabolism and biological properties. J. Nutr. Biochem. 2004, 15, 2-11. [CrossRef]

11. Ponce, F.; Mirabal-Gallardo, Y.; Versari, A.; Laurie, F.; Versari, A. The use of cation exchange resins in wines: Effects on $\mathrm{pH}$, tartrate stability, and metal content. Cienc. E Investig. Agrar. 2018, 45, 82-92. [CrossRef]

12. Jordão, A.M.; Cosme, F. Recent advances in wine stabilization and conservation technologies; Nova Publishers: New York, NY, USA, 2016; ISBN 978-1-63484-883-1.

13. Ibeas, V.; Correia, A.C.; Jordão, A.M. Wine tartrate stabilization by different levels of cation exchange resin treatments: Impact on chemical composition, phenolic profile and organoleptic properties of red wines. Food Res. Int. 2015, 69, 364-372. [CrossRef]

14. Kelly, N.; Kelly, A.; O'Mahony, J. Strategies for enrichment and purification of polyphenols from fruit-based materials. Trends Food Sci. Technol. 2019, 83, 248-258. [CrossRef]

15. Soto, M.L.; Moure, A.; Domínguez, H.; Parajó, J.C. Recovery, concentration and purification of phenolic compounds by adsorption: A review. J. Food Eng. 2011, 105, 1-27. [CrossRef]

16. Cassano, A.; Rastogi, N.K.; Basile, A. Membrane technologies for water treatment and reuse in the food and beverage industries. In Advances in Membrane Technologies for Water Treatment, 1st ed.; Basile, A., Cassano, A., Rastogi, N., Eds.; Woodhead Publishing: Sawston, UK, 2015; pp. 551-580, ISBN 978-1-78242-121-4.

17. Russo, C. A new membrane process for the selective fractionation and total recovery of polyphenols, water and organic substances from vegetation waters (VW). J. Membr. Sci. 2007, 288, 239-246. [CrossRef]

18. Bazinet, L.; Brianceau, S.; Dubé, P.; Desjardins, Y. Evolution of cranberry juice physico-chemical parameters during phenolic antioxidant enrichment by electrodialysis with filtration membrane. Sep. Purif. Technol. 2012, 87, 31-39. [CrossRef]

19. Bazinet, L.; Doyen, A. Antioxidants, mechanisms, and recovery by membrane processes. Crit. Rev. Food Sci. Nutr. 2015, 57, 677-700. [CrossRef]

20. Husson, E.; Araya-Farias, M.; Gagné, A.; Bazinet, L. Selective anthocyanins enrichment of cranberry juice by electrodialysis with filtration membrane: Influence of membranes characteristics. J. Membr. Sci. 2013, 448, 114-124. [CrossRef]

21. Achaerandio, I.; Güell, C.; López, F. New approach to continuous vinegar decolourisation with exchange resins. J. Food Eng. 2007, 78, 991-994. [CrossRef]

22. Coca, M.; Garcia, M.T.; Mato, S.; Cartón, A.; Gonzalez, G. Evolution of colorants in sugarbeet juices during decolorization using styrenic resins. J. Food Eng. 2008, 89, 429-434. [CrossRef]

23. Luo, J.; Guo, S.; Qiang, X.; Hang, X.; Chen, X.; Wan, Y. Sustainable utilization of cane molasses by an integrated separation process: Interplay between adsorption and nanofiltration. Sep. Purif. Technol. 2019, 219, 16-24. [CrossRef]

24. Zhang, Q.; Qian, X.; Tang, B. Environmentally friendly preparation of a strong basic anion exchange fibers and its application in sugar decolorization. React. Funct. Polym. 2014, 76, 41-48. [CrossRef]

25. Li, J.; Liang, L.; Cheng, J.; Huang, Y.; Zhu, M.; Liang, S. Extraction of pigment from sugarcane juice alcohol wastewater and evaluation of its antioxidant and free radical scavenging activities. Food Sci. Biotechnol. 2012, 21, 1489-1496. [CrossRef]

26. Zhang, J.; Singh, R.; Quek, S.Y. Extraction of anthocyanins from natural sources-Methods and commercial considerations. In Food Chemistry, Function and Analysis; Brooks, M.S.-L., Celli, G.B., Eds.; Royal Society of Chemistry: Cambridge, UK, 2019; pp. 77-105, ISBN 978-1-78801-215-7. 
27. Dul, V.N.; Dargaeva, T.D.; Kir'janov, A.A.; Sajbel', O.L.; Sokol'skaja, T.A.; Ferubko, E.V.; Shilina, N.L.; Gromakova, A.I. Method for producing therapeutic agent possessing antioxidant activity. R.U. Patent 2568 908 C1, 20 November 2015.

28. Milheiro, J.; Ferreira, L.C.; Filipe-Ribeiro, L.; Cosme, F.; Nunes, F.M. A simple dispersive solid phase extraction clean-up/concentration method for selective and sensitive quantification of biogenic amines in wines using benzoyl chloride derivatisation. Food Chem. 2019, 274, 110-117. [CrossRef] [PubMed]

29. Kammerer, D.R.; Kammerer, J.; Carle, R. Resin adsorption and ion exchange to recover and fractionate polyphenols. In Polyphenols in Plants; Watson, R.R., Ed.; Academic Press: New York, NY, USA, 2014; pp. 219-230, ISBN 978-0-12-397934-6.

30. Pradal, D.; Vauchel, P.; Decossin, S.; Dhulster, P.; Dimitrov, K. Integrated extraction-adsorption process for selective recovery of antioxidant phenolics from food industry by-product. Chem. Eng. Process. Process. Intensif. 2018, 127, 83-92. [CrossRef]

31. Mikhaylin, S.; Bazinet, L. Fouling on ion-exchange membranes: Classification, characterization and strategies of prevention and control. Adv. Colloid Interface Sci. 2016, 229, 34-56. [CrossRef] [PubMed]

32. Martín, J.; Díaz-Montaña, E.J.; Asuero, A.M.J.-M.A.A.G. Recovery of Anthocyanins Using Membrane Technologies: A Review. Crit. Rev. Anal. Chem. 2018, 48, 143-175. [CrossRef]

33. Kammerer, J.; Carle, R.; Kammerer, D.R. Adsorption and Ion Exchange: Basic Principles and Their Application in Food Processing. J. Agric. Food Chem. 2011, 59, 22-42. [CrossRef]

34. Buran, T.J.; Sandhu, A.K.; Li, Z.; Rock, C.R.; Yang, W.W.; Gu, L. Adsorption/desorption characteristics and separation of anthocyanins and polyphenols from blueberries using macroporous adsorbent resins. J. Food Eng. 2014, 128, 167-173. [CrossRef]

35. Zhao, Z.; Wu, M.; Jiang, Q.; Zhang, Y.; Chang, X.; Zhan, K. Adsorption and Desorption Studies of Anthocyanins from Black Peanut Skins on Macroporous Resins. Int. J. Food Eng. 2015, 11, 841-849. [CrossRef]

36. Wang, W.; Deng, J.; Shi, X.; Liu, Y. Isolation, purification and structure identification of anthocyanins from Vitis davidii Foex skin. Trans. Chin. Soc. Agric. Eng. 2016, 32, 296-301.

37. Zhang, P.; Wang, L.; Fang, S. Modeling of the Adsorption/Desorption Characteristics and Properties of Anthocyanins from Extruded Red Cabbage Juice by Macroporous Adsorbent Resin. Int. J. Food Eng. 2019, 15, 15. [CrossRef]

38. Soto, M.L.; Moure, A.; Domínguez, H.; Parajó, J. Batch and fixed bed column studies on phenolic adsorption from wine vinasses by polymeric resins. J. Food Eng. 2017, 209, 52-60. [CrossRef]

39. Yang, Y.; Yuan, X.; Xu, Y.; Yu, Z. Purification of Anthocyanins from Extracts of Red Raspberry Using Macroporous Resin. Int. J. Food Prop. 2015, 18, 1046-1058. [CrossRef]

40. Haddad, M.; Oie, C.; Duy, S.V.; Sauvé, S.; Barbeau, B. Adsorption of micropollutants present in surface waters onto polymeric resins: Impact of resin type and water matrix on performance. Sci. Total. Environ. 2019, 660, 1449-1458. [CrossRef]

41. Ulbricht, M.; Ansorge, W.; Danielzik, I.; König, M.; Schuster, O. Fouling in microfiltration of wine: The influence of the membrane polymer on adsorption of polyphenols and polysaccharides. Sep. Purif. Technol. 2009, 68, 335-342. [CrossRef]

42. Caetano, M.; Valderrama, C.; Farran, A.; Cortina, J.L. Phenol removal from aqueous solution by adsorption and ion exchange mechanisms onto polymeric resins. J. Colloid Interface Sci. 2009, 338, 402-409. [CrossRef]

43. Dąbrowski, A.; Podkościelny, P.; Hubicki, Z.; Barczak, M. Adsorption of phenolic compounds by activated carbon-A critical review. Chemosphere 2005, 58, 1049-1070. [CrossRef]

44. Rengaraj, S.; Moon, S.-H.; Sivabalan, R.; Arabindoo, B.; Murugesan, V. Agricultural solid waste for the removal of organics: Adsorption of phenol from water and wastewater by palm seed coat activated carbon. Waste Manag. 2002, 22, 543-548. [CrossRef]

45. Radhika, M.; Palanivelu, K. Adsorptive removal of chlorophenols from aqueous solution by low cost adsorbent-Kinetics and isotherm analysis. J. Hazard. Mater. 2006, 138, 116-124. [CrossRef]

46. Özkaya, B. Adsorption and desorption of phenol on activated carbon and a comparison of isotherm models. J. Hazard. Mater. 2006, 129, 158-163. [CrossRef]

47. Taktak, F.; Ciğeroğlu, Z.; Öğen, Y.; Kirbaşlar, Ş.I. Resin-loaded cationic hydrogel: A new sorbent for recovering of grapefruit polyphenols. Chem. Eng. Commun. 2018, 205, 1442-1456. [CrossRef]

48. Kaushik, A.; Basu, S.; Raturi, S.; Batra, V.; Balakrishnan, M. Recovery of antioxidants from sugarcane molasses distillery wastewater and its effect on biomethanation. J. Water Process. Eng. 2018, 25, 205-211. [CrossRef] 
49. Vidal, R.H.L.; Pereira, C.G. Ion exchange resin applied to obtain the clarified cashew juice. Sep. Sci. Technol. 2015, 150707113216002. [CrossRef]

50. Sholokhova, A.Y.; Eliseeva, T.; Voronyuk, I.V. Sorption of Vanillin by Highly Basic Anion Exchangers under Dynamic Conditions. Russ. J. Phys. Chem. A 2018, 92, 2048-2052. [CrossRef]

51. Robbins, R.D.; Johnson, D.K.; Collinz, T.M.; Ahmadiani, N.; Giusti, M.M. Method of Isolating Blue Anthocyanin Fractions. U.S. Patent 10119029 B2, 6 November 2018.

52. Yang, L.; Tan, T. Enhancement of the isolation selectivity of isoflavonoid puerarin using oligo- $\beta$-cyclodextrin coupled polystyrene-based media. Biochem. Eng. J. 2008, 40, 189-198. [CrossRef]

53. Geng, X.; Ren, P.; Pi, G.; Shi, R.; Yuan, Z.; Wang, C. High selective purification of flavonoids from natural plants based on polymeric adsorbent with hydrogen-bonding interaction. J. Chromatogr. A 2009, 1216, 8331-8338. [CrossRef] [PubMed]

54. Ghafari, M.; Cui, Y.; Alali, A.; Atkinson, J.D. Phenol adsorption and desorption with physically and chemically tailored porous polymers: Mechanistic variability associated with hyper-cross-linking and amination. J. Hazard. Mater. 2019, 361, 162-168. [CrossRef]

55. Kammerer, J.; Boschet, J.; Kammerer, D.R.; Carle, R. Enrichment and fractionation of major apple flavonoids, phenolic acids and dihydrochalcones using anion exchange resins. LWT 2011, 44, 1079-1087. [CrossRef]

56. Kammerer, J.; Schweizer, C.; Carle, R.; Kammerer, D.R. Recovery and fractionation of major apple and grape polyphenols from model solutions and crude plant extracts using ion exchange and adsorbent resins. Int. J. Food Sci. Technol. 2011, 46, 1755-1767. [CrossRef]

57. Zhang, K.; Yang, S.-T. Effect of $\mathrm{pH}$ on Fumaric Acid Adsorption onto IRA900 Ion Exchange Resin. Sep. Sci. Technol. 2014, 50, 56-63. [CrossRef]

58. Hashim, H.; Wan Ahmad, W.Y.; Zubairi, S.I.; Maskat, M.Y. Effect of $\mathrm{pH}$ on adsorption of organic acids and phenolic compounds by amberlite ira 67 resin. J. Teknol. 2018, 81. [CrossRef]

59. Lasanta, C.; Caro, I.; Perez, L. The influence of cation exchange treatment on the final characteristics of red wines. Food Chem. 2013, 138, 1072-1078. [CrossRef] [PubMed]

60. Chorfa, N.; Savard, S.; Belkacemi, K. An efficient method for high-purity anthocyanin isomers isolation from wild blueberries and their radical scavenging activity. Food Chem. 2016, 197, 1226-1234. [CrossRef]

61. Meile, K.; Iljina, N.; Zhurinsh, A. Desorption of Phenols from Anion Exchange Resins after the Separation of Wood Pyrolysis Products. Key Eng. Mater. 2019, 800, 256-260. [CrossRef]

62. Meng, L.; Zhu, J.; Ma, Y.; Sun, X.; Li, D.; Li, L.; Bai, H.; Xin, G.; Meng, X. Composition and antioxidant activity of anthocyanins from Aronia melanocarpa cultivated in Haicheng, Liaoning, China. Food Biosci. 2019, 30, 100413. [CrossRef]

63. Shuang, C.; Wang, J.; Li, H.; Li, A.; Zhou, Q. Effect of the chemical structure of anion exchange resin on the adsorption of humic acid: Behavior and mechanism. J. Colloid Interface Sci. 2015, 437, 163-169. [CrossRef]

64. Liu, S.; Wang, J.; Huang, W.; Tan, X.; Dong, H.; Goodman, B.A.; Du, H.; Lei, F.; Diao, K. Adsorption of phenolic compounds from water by a novel ethylenediamine rosin-based resin: Interaction models and adsorption mechanisms. Chemosphere 2019, 214, 821-829. [CrossRef]

65. Giles, C.H.; Smith, D.; Huitson, A. A general treatment and classification of the solute adsorption isotherm. I. Theoretical. J. Colloid Interface Sci. 1974, 47, 755-765. [CrossRef]

66. Traynor, M.; Ahmad, I. Impact of a commercially available ion-exchange resin used in red wines to reduce toxic compounds: Effect on $\mathrm{pH}$, oxidation-reduction potential, color, and sensory attributes. J. Food Sci. Technol. 2018, 55, 4859-4866. [CrossRef]

67. Zhao, H.; Wu, W.; Yao, B.; Fang, L.; Li, W. Study on deacidification process of blackberry juice. Acta Hortic. 2016, 237-244. [CrossRef]

68. Zhang, J.; Zhou, X.; Wang, D.; Zhou, X.; Tan, S. Methylation Formation to Improve Red Radish Anthocyanins Solubility in Cold Water. Int. J. Chem. Eng. Appl. 2013, 221-223. [CrossRef]

69. Ricci, A.; Olejar, K.J.; Parpinello, G.P.; Kilmartin, P.A.; Versari, A. Application of Fourier Transform Infrared (FTIR) Spectroscopy in the Characterization of Tannins. Appl. Spectrosc. Rev. 2015, 50, 407-442. [CrossRef]

70. Murugananthan, M.; Raju, G.B.; Prabhakar, S. Removal of tannins and polyhydroxy phenols by electro-chemical techniques. J. Chem. Technol. Biotechnol. 2005, 80, 1188-1197. [CrossRef]

71. Mohammed-Ziegler, I.; Billes, F. Vibrational spectroscopic calculations on pyrogallol and gallic acid. J. Mol. Struct. Theochem. 2002, 618, 259-265. [CrossRef]

72. Nakanishi, K.; Solomon, P.H. Infrared Absorption Spectroscopy, 2nd ed.; Holden-Day: Oakland, CA, US, 1977. 
73. Socrates, G. Infrared and Raman Characteristic Group Frequencies: Tables and Charts, 3rd ed.; Wiley: Chichester, UK, 2010; ISBN 978-0-470-09307-8.

74. Pappas, C.; Takidelli, C.; Tsantili, E.; Tarantilis, P.; Polissiou, M. Quantitative determination of anthocyanins in three sweet cherry varieties using diffuse reflectance infrared Fourier transform spectroscopy. J. Food Compos. Anal. 2011, 24, 17-21. [CrossRef]

75. García-Tejeda, Y.V.; Salinas-Moreno, Y.; Hernandez-Martinez, A.R.; Martínez-Bustos, F. Encapsulation of Purple Maize Anthocyanins in Phosphorylated Starch by Spray Drying. Cereal Chem. J. 2016, 93, 130-137. [CrossRef]

76. Baranović, G.; Šegota, S. Infrared spectroscopy of flavones and flavonols. Reexamination of the hydroxyl and carbonyl vibrations in relation to the interactions of flavonoids with membrane lipids. Spectrochim. Acta Part A Mol. Biomol. Spectrosc. 2018, 192, 473-486. [CrossRef]

77. Laghi, L.; Versari, A.; Parpinello, G.P.; Nakaji, D.Y.; Boulton, R.B. FTIR Spectroscopy and Direct Orthogonal Signal Correction Preprocessing Applied to Selected Phenolic Compounds in Red Wines. Food Anal. Methods 2011, 4, 619-625. [CrossRef]

78. Silva, S.D.; Feliciano, R.P.; Boas, L.V.; Bronze, M.R. Application of FTIR-ATR to Moscatel dessert wines for prediction of total phenolic and flavonoid contents and antioxidant capacity. Food Chem. 2014, 150, 489-493. [CrossRef]

79. Tinti, A.; Tugnoli, V.; Bonora, S.; Francioso, O. Recent applications of vibrational mid-Infrared (IR) spectroscopy for studying soil components: A review. J. Central Eur. Agric. 2015, 16, 1-22. [CrossRef]

80. Günzler, H.; Gremlich, H.-U. IR Spectroscopy: An Introduction; Wiley-VCH: Weinheim, Germany, 2002; ISBN 978-3-527-28896-0.

81. Vasil'Eva, V.I.; Goleva, E.A.; Selemenev, V.F. Features of the sorption of phenylalanine by profiled ion-exchange membranes. Russ. J. Phys. Chem. A 2016, 90, 2035-2043. [CrossRef]

82. Grebeniyk, V.D.; Mazo, A.A. Water Demineralization with Ion Exchangers; Chemistry: Moscow, Russia, 1982. (In Russian)

83. Pashkov, A.B.; Saldadze, K.M.; Lukyanova, N.L.; Polyakova, T.A. GOST 20301-74. Ion-Exchange Resins. Anionites. Specifications; Izdatel'stvo standartov: Moscow, Russia, 1992.

84. Kravchenko, T.A.; Sakardina, E.A.; Kalinichev, A.I.; Zolotukhina, E.V. Stabilization of copper nanoparticles with volume- and surface-distribution inside ion-exchange matrices. Russ. J. Phys. Chem. A 2015, 89, 1648-1654. [CrossRef]

85. Helfferich, F. Ion Exchange; McGraw-Hill: New York, NY, USA, 1962; ISBN 0-486-68784-8.

86. Moskvichev, V.; Yurchenko, V.S.; Genedi, A.S.; Chokina, B.C.; Samsonov, G.V. Synthesis, Structure, and Properties of Polymers; Nauka: Leningrad, Russia, 1970. (In Russian)

87. Bdiri, M.; Dammak, L.; Chaabane, L.; Larchet, C.; Hellal, F.; Nikonenko, V.; Pismenskaya, N. Cleaning of cation-exchange membranes used in electrodialysis for food industry by chemical solutions. Sep. Purif. Technol. 2018, 199, 114-123. [CrossRef]

88. Semushin, A.M.; Yakovlev, V.A.; Ivanova, E.V. Infrared Absorption Spectra of Ion-Exchange Materials. Reference Guide; Himiya: Leningrad, Russia, 1980. (In Russian)

89. Uglyanskaya, V.A.; Chikin, G.A.; Selemenev, V.F.; Zav'yalova, V.A. Infrared Spectroscopy of Ion-Exchange Materials; VSU: Voronezh, Russia, 1989. (In Russian)

90. Maes, A.M.; Pandey, T.P.; Vandiver, M.A.; Lundquist, L.K.; Yang, Y.; Horan, J.L.; Krosovsky, A.; Liberatore, M.; Seifert, S.; Herring, A.M. Preparation and characterization of an alkaline anion exchange membrane from chlorinated poly(propylene) aminated with branched poly(ethyleneimine). Electrochim. Acta 2013, 110, 260-266. [CrossRef]

91. Holyavka, M.G.; Kovaleva, T.A.; Artyukhov, V.G.; Karpov, S.I.; Seredin, P.V.; Bogachev, M.I. The research of interaction mechanism for inulinase molecule with the matrix of synthetic ionites. Fundam. Res. 2013, 4, 663-671.

92. Lewis, J. The New Color Mixing Companion: Explore and Create Fresh and Vibrant Color Palettes with Paint, Collage, And Mixed Media; Quarry Books, an imprint of The Quarto Group: Beverly, MA, USA, 2018; ISBN 978-1-63159-549-3.

93. Sarapulova, V.; Nevakshenova, E.; Nebavskaya, X.; Kozmai, A.; Aleshkina, D.; Pourcelly, G.; Nikonenko, V.V.; Pismenskaya, N. Characterization of bulk and surface properties of anion-exchange membranes in initial stages of fouling by red wine. J. Membr. Sci. 2018, 559, 170-182. [CrossRef] 
94. Koter, S.; Kultys, M. Modeling the electric transport of sulfuric and phosphoric acids through anion-exchange membranes. Sep. Purif. Technol. 2010, 73, 219-229. [CrossRef]

95. Ramírez, P.; Alcaraz, A.; Mafe, S.; Pellicer, J. Donnan Equilibrium of Ionic Drugs in pH-Dependent Fixed Charge Membranes: Theoretical Modeling. J. Colloid Interface Sci. 2002, 253, 171-179. [CrossRef]

96. Franck-Lacaze, L.; Sistat, P.; Huguet, P. Determination of the pKa of poly (4-vinylpyridine)-based weak anion exchange membranes for the investigation of the side proton leakage. J. Membr. Sci. 2009, 326, 650-658. [CrossRef]

97. Yoon, S.Y.; Choi, W.J.; Park, J.M.; Yang, J.-W. Selective adsorption of flavonoid compounds from the leaf extract of Ginkgo bilobaL. Biotechnol. Tech. 1997, 11, 553-556. [CrossRef]

98. Fu, B.; Liu, J.; Li, H.; Li, L.; Lee, F.S.; Wang, X. The application of macroporous resins in the separation of licorice flavonoids and glycyrrhizic acid. J. Chromatogr. A 2005, 1089, 18-24. [CrossRef] [PubMed]

99. Merle, G.G.; Wessling, M.M.; Nijmeijer, D.K. Anion exchange membranes for alkaline fuel cells: A review. J. Membr. Sci. 2011, 377, 1-35. [CrossRef]

100. Kozmai, A.; Nikonenko, V.; Zyryanova, S.; Pismenskaya, N.; Dammak, L.; Baklouti, L. Modelling of anion-exchange membrane transport properties with taking into account the change in exchange capacity and swelling when varying bathing solution concentration and pH. J. Membr. Sci. 2019, 590, 117291. [CrossRef]

101. Higa, M.; Tanaka, N.; Nagase, M.; Yutani, K.; Kameyama, T.; Takamura, K.; Kakihana, Y. Electrodialytic properties of aromatic and aliphatic type hydrocarbon-based anion-exchange membranes with various anion-exchange groups. Polymer 2014, 55, 3951-3960. [CrossRef]

102. Harmon, K.M.; De Santis, N.J.; Brandt, D.O. Hydrogen bonding Part 39. Hydrogen bonding by $\alpha-\mathrm{CH}$ in quaternary ammonium salts and the possible role of $\mathrm{CH} \cdots$ B hydrogen bonds in acetylcholine-Receptor interactions. J. Mol. Struct. 1992, 265, 47-57. [CrossRef]

103. Pan, B.; Xiong, Y.; Li, A.; Chen, J.; Zhang, Q.; Jin, X. Adsorption of aromatic acids on an aminated hypercrosslinked macroporous polymer. React. Funct. Polym. 2002, 53, 63-72. [CrossRef]

104. Miguel, M.G. Anthocyanins: Antioxidant and/or anti-inflammatory activities. J. Appl. Pharm. Sci. 2011, 1, 7-15.

105. Pawlak-Lemańska, K.; Szymusiak, H.; Tyrakowska, B.; Zieliński, R.; Soffers, A.E.; Rietjens, I.M.C.M. The influence of $\mathrm{pH}$ on antioxidant properties and the mechanism of antioxidant action of hydroxyflavones. Free. Radic. Biol. Med. 2001, 31, 869-881. [CrossRef]

106. De Smedt, C.; Ferrer, F.; Leus, K.; Spanoghe, P. Removal of Pesticides from Aqueous Solutions by Adsorption on Zeolites as Solid Adsorbents. Adsorpt. Sci. Technol. 2015, 33, 457-485. [CrossRef]

107. Ebadi, A.; Soltan, J.; Khudiev, A. What is the correct form of BET isotherm for modeling liquid phase adsorption? Adsorption 2009, 15, 65-73. [CrossRef]

108. Sing, K.S.W. Reporting physisorption data for gas/solid systems with special reference to the determination of surface area and porosity (Recommendations 1984). Pure Appl. Chem. 1985, 57, 603-619. [CrossRef]

109. Foo, K.; Hameed, B. Insights into the modeling of adsorption isotherm systems. Chem. Eng. J. 2010, 156, 2-10. [CrossRef]

110. Bdiri, M.; Perreault, V.; Mikhaylin, S.; Larchet, C.; Hellal, F.; Bazinet, L.; Dammak, L. Identification of phenolic compounds and their fouling mechanisms in ion-exchange membranes used at an industrial scale for wine tartaric stabilization by electrodialysis. Sep. Purif. Technol. 2020, 233, 115995. [CrossRef]

111. Moreno-Arribas, M.V.; Polo, M.C. (Eds.) Wine Chemistry and Biochemistry; Springer: New York, NY, USA, 2009; ISBN 978-0-387-74116-1.

112. Sholokhova, A.Y.; Eliseeva, T.; Voronyuk, I.V. Sorption of vanillin on highly basic anion exchanger under static conditions. Russ. J. Phys. Chem. A 2017, 91, 2237-2243. [CrossRef]

113. Sholokhova, A.Y.; Eliseeva, T.V.; Buryak, A.K. The Influence of Experimental Factors on the Sorption of Vanillin by a Macroporous Highly Basic Anion Exchanger with a Low Degree of Cross-Linking. Colloid J. 2019, 81, 621-625. [CrossRef]

114. Giles, C.H.; D'Silva, A.P.; A Easton, I. A general treatment and classification of the solute adsorption isotherm part. II. Experimental interpretation. J. Colloid Interface Sci. 1974, 47, 766-778. [CrossRef] 
115. Giusti, M.; Wrolstad, R.E. Characterization and Measurement of Anthocyanins by UV-Visible Spectroscopy. Curr. Protoc. Food Anal. Chem. 2001, F1.2.1-F1.2.13. [CrossRef]

116. Wrolstad, R.E. Anthocyanin Pigments-Bioactivity and Coloring Properties. J. Food Sci. 2006, 69, C419-C425. [CrossRef]

Publisher's Note: MDPI stays neutral with regard to jurisdictional claims in published maps and institutional affiliations.

(C) 2020 by the authors. Licensee MDPI, Basel, Switzerland. This article is an open access article distributed under the terms and conditions of the Creative Commons Attribution (CC BY) license (http://creativecommons.org/licenses/by/4.0/). 